\title{
International Entrepreneurial Startups Location under uncertainty through a Heterogeneous Multi-Layer Decision Making Approach: Evidence and Application of an Emerging Economy
}

\author{
Seyed Hossein Razavi Hajiagha \\ Department of Management \\ Khatam University, Tehran, Iran \\ h.razavi@,khatam.ac.ir \\ Niloofar Ahmadzadeh Kandi \\ Sydney Business School, Advanced MBA, \\ University of Wollongong, Wollongong, NSW, 2522, Australia \\ Nak127@uowmail.edu.au
}

Hannan Amoozad Mahdiraji ${ }^{1,2}$

${ }^{1}$ Leicester Castle Business School

Faculty of Business and Law, De Montfort University

Leicester, United Kingdom

hannan.amoozadmahdiraji@dmu.ac.uk

${ }^{2}$ Faculty of Management,

University of Tehran, Tehran, Iran

h.amoozad@ut.ac.ir

\section{Vahid Jafari Sadeghi}

Northumbria University Newcastle Business School

Newcastle upon Tyne, UK

vahid.jafari-sadeghi@northumbria.ac.uk

Shide Sadat Hashemi

Executive Manager, Saramadan Andishe Avina Co.

Science and technology park

Tarbiat Modares University, Tehran, Iran (corresponding author) consultant.mgg@gmail.com 


\title{
International Entrepreneurial Startups Location under uncertainty through a Heterogeneous Multi-Layer Decision Making Approach: Evidence and Application of an Emerging Economy
}

\begin{abstract}
Purpose. Science and Technology Parks (STPs) have a limited capacity, which can create challenging conditions for applicants. This makes the location selection a multi-criteria decision-making (MCDM) problem to find and apply for the most appropriate STP with the highest accordance with the startup's requirements. This research aims to select the most appropriate Science and Technology Park to locate an international entrepreneurial pharmaceutical startup under uncertainty. Since drugs are generally produced domestically in developing countries such as Iran, the access of pharmaceutical startups to the resources provided by STPs can lead to overcoming competitors and improving the country's health system.
\end{abstract}

Method. In this research, the factors or attributes effective on startup location were extracted through a two-round Delphi method which was performed among 15 experts within 3 groups. Subsequently, the determining factors were used to select the location of a pharmaceutical startup among possible STPs. In this regard, decision-makers were allowed to use different types of numbers to transfer their opinion. Afterward, the Heterogeneous Weighted Aggregated Sum Product Assessment Method (HWASPAS) method was applied to calculate the score of each alternative and rank them to place the studied startup successfully.

Results. The results indicated that Tehran STP stands in the first place; however, if the decision was made based on single criteria like cost, some other STPs could be preferable and many managers would lose this choice. Furthermore, the results of the proposed method were close to other popular heterogeneous MCDM approaches.

Originality. A heterogeneous WASPAS is developed in this article for the first time to enable international entrepreneurs to imply their opinion with various values and linguistic variables to reduce the emphasis on accurate data in an uncertain environment.

Keywords. STPs Location, Delphi Method, Entrepreneurial Startups, Heterogeneous WASPAS. 


\section{Introduction}

Innovation and creation are two important and inevitable concepts in the international entrepreneurship competitive atmosphere. Entrepreneurship and establishing a business and dealing with the increasing speed of creations, transformations, and transactions need a compromising attitude such as a growth-oriented approach (Mason and Brown, 2014), quick responsiveness (Williams et al., 2017), agile processes and mechanism (Silva et al., 2019), flexibility (Shi et al., 2016) and competitive culture (Molina-Morales et al., 2011), etc. Therefore, firms should survive through innovative capabilities as their valuable assets. This is tightly dependent on critical elements and factors such as organization human resources, organizational structure, core competency, main innovative idea, international competitors, firm location, investment, organization knowledge, technology infrastructure, etc. In this regard, many studies illustrated that corporate location (as mentioned above) has a significant effect on firm performance and innovation capacity (Brcic et al., 2010; Chen and Hsiao, 2013; Vásquez-Urriago et al., 2016; Ferreira et al., 2017; Chen et al., 2019; Dohse and Schnier, 2019). However, some researchers claim that a stronger pro-business environment can lead to a higher level of innovation (Chen et al., 2019) and even their effects are different in various critical factors (Lai and Shyu, 2005). For this purpose, Science and Technology Parks (STPs) and university parks are created to facilitate and accelerate the entrepreneur firms to improve and achieve their professional goals more quickly (Sun et al., 2019). As the university is one place to learn and earn knowledge innovation and techno0logies, university parks are the ecosystems that accelerate the transformation of science and knowledge to technological achievements (Tang, 2017). They are considered catalyzers in economic and industrial development for entrepreneurs (Gursel, 2014). Due to international relationships among universities and their alumni, these parks are capable to extend these relationships toward more innovative international products and services (Kaloudis and Svoboda, 2019).

Scholars previously proved that the geographical proximity provided through STPs develops a dynamic cluster that leads to promoting competitive advantages and accelerating economic growth through diffusing knowledge and technology and innovation among and between universities and firms (Almeida et al., 2020). Additionally, STPs provide organizations with the opportunity to innovate in an open system, as science and technology parks serve as an intermediary between technology developers and technology disseminators and transfer innovations from universities and laboratories to the market. Due to the networking nature of STPs, they are mediators and providers of open innovation for universities, research laboratories, startups, and organizations (Şimşek and Yıldırım, 2016). Besides, the "global village" concept manifests through different aspects such as global knowledge which necessitates real international relationships and interactions among scientists and innovative entities while vast and universal events like COVID 19 pandemic. Along with this crisis, there should be a synergic international approach to lead to fewer tensions and finding solutions innovatively. As STPs can internationally connect and transfer knowledge directly, it accelerates the process of dealing with unknown and undesirable creatures and situations (Hobbs et al., 2017).

The first generation of STPs goes back to the 1950s, on the model of Stanford University, with business and R\&D laboratories that associations founded the Stanford industrial park in 1951. Now it is known as Silicon Valley. STPs provide locations that lead to innovation and development and also facilities the commercialization of technology, where governments, universities, and private companies may collaborate. Science parks are often located close to universities and communicate continuously. Usually, governments assign remarkable 
resources to these parks to promote research-based industrial and innovative achievements as their mission (Lai and Shyu, 2005). A science park location provides clusters that are geographically close together and concentrated, geographical proximity reduces uncertainty and search costs (Link and Scott, 2019) and increases the chance of finding innovation partners. This causes similar situations and factors such as government policy, legal rules, capital market aspects, factor costs, etc., which may be similar in the same area (Lai and Shyu, 2005). Locating close to similar firms helps to find the critical common resources easily with long-lasting relations which reduces the cost of time waste (Vásquez-Urriago et al., 2016). Therefore, this led to emerging of the term "Entrepreneurial Ecosystem" with an important role in small firm's development (Pugh et al., 2021). Growing entrepreneurial activities as the result of greater social capital (Hansson et al., 2005), increasing survival rates and research productivity (Lamperti et al., 2017), having more patenting activities (Squicciarini, 2008), and improving the performance and success of the innovation activities (McCann and Folta, 2008) are some of the reasons that startups benefit from locating at STPs. Based on Johansson and Lööf, (2008), firms are more likely to be innovative in more developed regions; therefore, STPs are not apart from this argument (Johansson and Lööf, 2008). Moreover, in less developed regions, the lack of useful and valuable inputs can be compensated by STPs which improve the innovation enclaves to embrace top entrepreneurs and scientists and boost the region's overall image (Hervas-Oliver and Albors-Garrigos, 2014). Furthermore, in lagging regions, where competition is predominantly local, the advantages of on-park organizations over their rivals may be seen (Albahari et al., 2016). This problem may be more highlighted among international entrepreneurial companies (Klyucharev et al., 2017).

An empirical study conducted at Tsinghua STP in Beijing for software-related companies found that more than 50 percent of firms with a technology background located in the Science and Technology Park have higher innovation performance (Motohashi, 2013).

Another empirical study of data from 365 manufacturing organizations in the ICT sector in Taiwan shows that firms located in science and technology parks benefit more from R\&D capability and innovation performance (Huang et al., 2012). Therefore, according to previous research on the location of technology-based organizations in science and technology parks, its direct effects can be seen in cases such as research and development, better innovation performance, and so on. The studied organization is in the field of the pharmaceutical industry, which is a knowledge-based organization with a technological background. Innovative and knowledge-based pharmaceutical corporates essentially need incubator centers and STPs to locate for primary years to facilitate the resourcing and speed up the production and supply of medicines. The pharmaceutical industry is one of the industrial sectors mostly concentrated on R\&D, which relies highly on complex knowledge (Gassmann and Reepmeyer, 2005). Furthermore, based on previous innovation research, one of the critical determinants of pharmaceutical companies' capabilities is the access to knowledge and their success to bring drugs to the market (Bignami et al., 2019). Moreover, the geographic concentration of firms provides them with the co-location of complementary resources. The STPs are considered as the core and hub of knowledge ecosystem and innovation resource for located startups (Mian and Hulsink, 2009). Additionally, the formation of alliances increases innovation, organizational learning, and creditability among shareholders. The most significant production factors in the pharmaceutical industry are the proximity to science centers, accessibility to skilled labor and talent pools, access to venture capitalists, and different sources of funds (Robaczewska et al., 2019). 
The location of pharmaceutical companies is one of the main components of the health system in the innovation and supply of new drugs in developing countries, especially Iran, where most of the main demands are provided by domestic drug companies. As "location" is a competitive variable and advantage for pharmaceutical companies compared with other companies (Walcott, 2001); therefore, the location of pharmaceutical startups is of special importance and can disrupt the efficiency of the country's health system. The main purpose of this study is to identify the best place to establish pharmaceutical startups in Iran, considering the complex nature of decision-making using multi-criteria decision-making.

According to the importance of location factor on corporates success, it is rarely seen that researchers concentrate on location selection in the case of startups and entrepreneurs. Due to the process of analyzing complex decisions to select the best place, multiple conflicting criteria for an evaluation in uncertain circumstances imply. That is why heterogeneous contexts are generally used to show this imprecision and hesitation (Estrella et al., 2017). Previous studies mostly focused on empirical studies, statistical tools like regression and testing hypotheses, and interviews instead of using more applicable tools. However, MADM methods can prioritize and rank the location options considering various cost or benefits criteria with different weights. The MADM methods are suitable to rank and prioritize the alternatives in many applications (Razavi Hajiagha et al., 2012; Zavadskas et al., 2015; Hajiagha et al., 2015a; Akcan and Güldeş, 2019; Chowdhury and Paul, 2020). The purpose of multi-attribute decision-making methods (MADM) is to select the best option or to weigh the decision factors. Each decision-making method has a specific task including ranking the alternatives, evaluating criteria, and extracting the relationship among the factors. AHP, TOPSIS, SAW, DEMATEL, VIKOR ELECTRE, and PROMETHEE are some of the MADM methods applied for location selection by other scholars (Razavi Hajiagha and Ahmadzadeh Kandi, 2021) This research aims to select the most appropriate Science and Technology Park to locate the NAD Co., a pharmaceutical corporate considering the effective criteria under uncertainty. Since location is a long-term and strategic decision (RamirezNafarrate et al., 2021), it is necessary to consider different criteria that are usually conflicting and uncertain. And representing different criteria using a single information representation is difficult (Yingying et al., 2020) and experts participating in the decision-making process prefer to express their opinions in any form that are more comfortable for them (MorenteMolinera et al., 2020), a heterogeneous WASPAS is developed to enable experts to imply their opinion with various values and linguistic variables to reduce the emphasis on accurate data in an uncertain environment. The WASPAS method is used as the multi-criteria decision-making method due to its acceptance among scholars (Mardani, et al., 2017). Combining weighted sum and weighted product methods, WASPAS elicits the advantages of both, and this can increase the accuracy and reliability of decisions (Baykasoğlu and Gölcük, 2019; Hashemnkhani Zolfani et al., 2013). Moreover, WASPAS can identify alternative rankings through optimal parameter combinations, minimize personal judgments, and provide an effective expert perspective which is the advantage of this method over other MADM methods.

The remainder of this paper is organized as follows. Section 2 reviews the relevant literature on the location of startups, the location of pharmaceutical companies, the location of pharmaceutical startups on the creation and diffusion of knowledge and their innovative and entrepreneurial activities, and the location selection process using MCDM methods. Next, section 3 explains the research methodology including the heterogeneous WASPAS, in section 4 the case study is investigated, and the implication, discussion, and conclusion are illustrated in sections 5 and 6 , relatively. 


\section{Literature review}

This study aims to select the best location for startups considering various criteria which leads to a multi-criteria decision-making problem. Therefore, a mixed methodology is employed, using the literature review, Delphi, and WASPAS methods to extract and evaluate the criteria while the respondents with different levels of knowledge and information about the criteria have participated in this study. In the following, the theoretical background and relevant literature have been discussed.

\subsection{STPs and Startups Location}

The relationship between universities and firms will be facilitated and strengthened through geographical proximity provided in science and technology parks and raises the synergy between academic institutes and firms and establishes human resources links. Previous research has proved that the geographical proximity provided through science and technology parks develops a dynamic cluster which leads to promoting competitive advantages and accelerating economic growth through diffusing knowledge and technology and innovation among and between universities and firms. Therefore, the abstract invention created by university experts needs entrepreneurs to transform them into marketable products to be considered as innovation. It has been proved that the agglomeration of universities, firms, and other knowledge-based organizations is lucrative for knowledge creation and its transfer (Ponds et al., 2010). On the other hand, STPs provide platforms for organizations to innovate in an open system due to the nature of the network that exists between universities, laboratories, startups, and small and large companies (Şimşek and Yıldırım, 2016).

Startups located in the parks emphasize more on innovative abilities since they have greater access to universities' scholars and research facilities; thus, science parks are considered as enclaves for development and innovation. Moreover, the correlation between geographical proximity and collaboration for innovation in STPs is considered as one of the most fundamental aspects of knowledge flows and a source of innovation because firstly, this facilitates linkages such as meetings and conversations which may lead to a cooperative project. Secondly, geographical proximity reduces uncertainty and decreases the transaction costs in collaborative projects derived from building trusts and long-lasting relationships, which leads to sharing more valuable and intangible knowledge (Abramovsky and Simpson, 2011). Based on Johansson and Lööf, (2008), firms are more likely to be innovative in more developed regions; therefore, STPs are not apart from this argument. The geographical proximity of organizations such as pharmaceutical firms helps them to have more strong links and sustained interactions in innovation processes that require constant collaborations or knowledge exchanges with partners. Therefore, the geography of high-tech and knowledgebased organizations such as pharmaceutical firms show that the connection between geography and innovation mainly depends on knowledge and technology interactions, which emphasizes a dynamic co-evolutionary of the pharmaceutical sector clustering (Hamdouch and Moulaert, 2006).

This industry is one of the industrial sectors mostly concentrated on $R \& D$, which relies highly on complex knowledge (Gassmann and Reepmeyer, 2005). The communication and knowledge exchange might be facilitated in short distances through personal and social interactions, casual meetings, and trust-building (Ponds et al., 2010). Note that the geographical proximity in pharmaceutical companies increases collaboration intensity 
between knowledge-based companies. A gravity model for estimating this collaboration intensity between organizations is provided by national and international organizations (Plotnikova and Rake, 2013). Moreover, the dimensions of proximity include geographical, cognitive, social, and cultural. Therefore, high transmission costs and planned meetings are the results of distance collaborations which make knowledge exchange more difficult. The complexity of knowledge and the coordination between different actors and sectors from various disciplines show the significance of geographical proximity in pharmaceutical firms. The type of knowledge being transferred in R\&D collaborations determines the importance of geographical proximity (Bignami et al., 2019). Universities have significant impacts on hightech and knowledge-intensive pharmaceutical startups, and the well-developed network and abundant venture capital increase the speed of commercialization. Organizing the location of startups in a particular region has been increased with the number of different firms in that area that promotes agglomeration economies. The geographical proximity affects biotechnology companies, expertise resources, skilled labor, and venture capitalists in specific locations, and the performance of biotechnology organizations (Stuart and Sorenson, 2003). The geographic cluster of pharmaceutical startups would enhance communication and knowledge sharing interaction in the R\&D network; nonetheless, it rarely raises innovation capabilities (Allen et al., 2016). Organizing the location of startups in a particular region has been increased with the number of different firms in that area that promotes agglomeration economies. Agglomeration economies might be generated through several processes (Stuart and Sorenson, 2003). One of the potentials is the overflowing of knowledge in the geographical proximity of firms. Accordingly, high-technology startups such as pharmaceutical startups may choose locations that facilitate the opportunity of diffusing technical knowledge and paves the way for taking advantage of knowledge externalities, which are localized in STPs. The second one is the high concentration of specialized suppliers of specific kinds of firms in that particular area. For example, in Silicon Valley, startups can benefit from relevant suppliers, access to biological materials, cutting-edge laboratory facilities, intellectual property law, service providers, and consulting services in their field.

According to Stuart and Sorenson (2003), biotech and pharmaceutical startups require three resources existing at particular locations. First, firms concentrated in one location, such as STPs, are a great source of new ideas, and a knowledge ecosystem for new ventures provided through the density of experts. R\&D partnerships between pharmaceutical companies and other research institutes and universities are prevalent in this setting which leads to exploitative alliances such as capturing the value of technology (Rothaermel and Deeds, 2004). Second, as high-technology startups need capital, venture capital (VC) is frequently provided to startups since the geographical proximity promotes the firm and university spinoffs, where the interaction of entrepreneurs and venture capitalists increases (Lecuyer, 2006). Third, specialized human capitals and talent pools are in demand for high-tech companies, and existing organizations and university experts provide skilled expertise trained for prospective startups (Stuart and Sorenson, 2003). Table 1 demonstrates the application of multi-criteria decision-making (MCDM) tools in location problems for different organizations.

\section{Insert Table 1}

According to the literature view, we find that the subject area of selecting the best location has always been the focus of researchers and organizations, while in the past they focused more on empirical studies, statistical methods, regression, and hypothesis testing, but today 
we find that the location selection is not a linear process, and many variables must be considered quantitatively or qualitatively in the subject of selection under uncertainty. In selecting the best location for startups, conditions of uncertainty are rarely considered in the literature and are mostly limited to fuzzy numbers. Therefore, a hybrid MADM method in the location selection for startups in the literature is scarce and conflict criteria have been considered rare in past research. Studies in the field of location and establishment of technology-based startups such as pharmaceutical companies in science and technology parks have not been well studied from an entrepreneurial perspective. In this regard, this paper's novelty is to employ a heterogeneous MCDM method to select the most appropriate location for startups, including comprehensive and conflict criteria, then rank the locations according to these criteria.

\section{Methodology}

In decision-making, the quantitative and qualitative characteristics of attributes are of equal importance, and to evaluate the research and involvement of individuals to provide alternatives, multiple formats of information must be considered, hence the heterogeneous decision-making method in this research has been used. Therefore, as different criteria include multiple information from quantitative and qualitative data, to facilitate the experts' participation in the decision-making process and review their ideas in any format, a heterogeneous WASPAS method has been developed, so that different values and linguistic variables can be evaluated in uncertain circumstances. HWASPAS includes several steps to be implemented completely. The proposed methodology consists of three major sections concentrating on (1) screening to extract the factors, (2) data gathering and, (3) HWASPAS. Each section includes some steps which trigger the next and frequent steps.

\section{$\underline{\text { Insert Figure } 1}$}

Screening. According to Figure 1 at the first step, the literature review indicates the related and affective factors. This step helps the research team extract criteria that influence the location selection decision. The location alternatives should be specified primarily based on available options; The created list of criteria will be considered as the basis of the Delphi questionnaire. The questionnaire is designed for the first round and then the experts' opinions will modify the factors. When the experts reach a consensus on the criteria, then the final refined list of criteria is obtained. Delphi method is a popular multistage method that is systematically used to collect, evaluate, and analyze the experts' opinions in the mentioned area without gathering people at the same time and place. Participants answer the questions in specific rounds and achieve each other's ideas and make a consensus after reviewing the answers of the rest of the group (Stefanidis et al., 2019). It involves a panel of 5 to 15 experts who imply their opinion through responding to a questionnaire in several rounds. In the first round, the panel member response to the first version of the questionnaire; the research team modifies it based on experts' opinions. The revised version is distributed for the second round. This time, the panel's members are asked to reply to the modified version, considering their first responses. This process continues until the panel reaches a consensus on the questionnaire. (Mokhtarzadeh et al., 2020). In the Delphi process people remain anonymous; it involves iteration and rounds; it is controlled to have feedbacks and responses are aggregated (Stefanidis et al., 2015). The outcome of this step leads to a set of finalized criteria which can be considered as decision criteria to rank the location alternatives.

Data gathering. The finalized set of criteria obtained through the Delphi method considers many commercial and scientific aspects. Regarding these various criteria and their different 
measures, the research team decided to set heterogeneous measurements to deal with criteria and allow the researchers and entrepreneurs to make the comparison. The alternatives information regarding the criteria set is extracted by different channels such as documents, websites, field research, questionnaire, etc. Then these heterogenous criteria are used to establish the decision matrix for the next step. This helps respondents to complete the matrices regardless of any measurement restrictions and problems. The experts and senior managers of the entrepreneurship team complete the matrix and imply their opinion toward different criteria. The decision matrix is provided in the next step, HWASPAS.

Heterogeneous WASPAS Preliminaries. In many real-world decision-making situations, uncertainty is an inevitable characteristic of the problem (Stewart, 2005). Different frameworks are proposed to aid decision-makers in dealing with uncertainty. Fuzzy sets theory is introduced as an extension of classic sets theory by attending a membership degree, e.g. $\mu$, to each element of the set. Fuzzy sets theory is extensively applied in multi-criteria decision-making problems. Reviewed studies illustrated a wide variety of its application in different MCDM problems (Kahraman, 2008; Afful-Dadzie et al., 2017). The application of fuzzy MCDM methods extends until recent years (Yadegaridehkordi, et al., 2020; Hussain et al., 2021). Some scholars believed the insufficiency of a single membership value portrays the uncertainty of the environment. Therefore, several extensions of fuzzy sets theory are proposed. The realm of this extension is usually to alleviate the need for certainty of membership degrees in FST (Bede, 2013). Intuitionistic fuzzy sets (IFS) (Atanassov, 1986) is an extension of FST where a non-membership degree, e.g. $v$, is also assigned to each element in a way that $\mu+v<1$. In an IFS, $1-\mu-v$ is defined as hesitancy. This hesitancy enabled decision-maker to consider his or her doubt and ambiguity in decision-making. IFSs are also applied extensively in decision-making problems (Afful-Dadzie et al., 2017). IFSs applications in MCDM continued in several newer studies (Xue and Deng, 2021; Ejegwa and Onyeke, 2021).

In many decision-making (DM) problems both qualitative and quantitative attributes are important. In these DM problems which precise calculation is almost unlikely, people's involvement is necessary to evaluate the attributes and assess the alternatives. In these situations, there may be different types of information such as triangular fuzzy numbers (TFNs), real numbers, intuitionistic fuzzy numbers, and interval numbers. Heterogeneous DM methods can include multiple formats of information (Wan and $\mathrm{Li}, 2013$; $\mathrm{Yu}$ et al., 2018). The attribute set $C$ can be categorized into $C_{1}=\left\{c_{1}, c_{2}, \ldots, c_{k_{1}}\right\}$ as real numbers, $C_{2}=$ $\left\{c_{k_{1}+1}, c_{k_{1}+2} \ldots, c_{k_{2}}\right\}$ as TFNs, $C_{3}=\left\{c_{k_{2}+1}, c_{k_{2}+2} \ldots, c_{k_{3}}\right\}$ as interval numbers and $C_{4}=$ $\left\{c_{k_{3}+1}, c_{k_{3}+2} \ldots, c_{k_{4}}\right\}$ as intuitionistic fuzzy numbers where $C_{k}(k=1,2,3,4)$ are expressed in heterogeneous situations with different numbers. Decision-makers also consist of a set $E=$ $\left\{e_{1}, e_{2} \ldots, e_{p}\right\}, E \in P$. Finally, the alternative set is determined as $A=\left\{a_{1}, a_{2} \ldots, a_{m}\right\}$ (Yu et al., 2018). $C_{k}$ can be supposed as both cost and benefit sets, represented by $C_{k}^{b}$ and $C_{k}^{c}$ respectively. Decision-makers evaluate the alternatives regarding attributes $\left(x_{i j}^{l}\right)$ through four types of numbers as follows.

$$
x_{i j}^{l}= \begin{cases}\hat{R}_{i j}^{l} & \left(c_{i} \in C_{1}\right) \\ {\left[\hat{a}_{i j}^{l}, \dot{\bar{a}}_{i j}^{l}\right]} & \left(c_{i} \in C_{2}\right) \\ \left(\dot{a}_{i j}^{l}, \hat{b}_{i j}^{l}, \hat{c}_{i j}^{l}\right) & \left(c_{i} \in C_{3}\right) \\ \left\langle\dot{\mu}_{i j}^{l}, \hat{v}_{i j}^{l}\right\rangle & \left(c_{i} \in C_{4}\right)\end{cases}
$$


Where $\hat{R}_{i j}^{l}$ indicates real numbers; $\left[\underline{a}_{i j}^{l}, \dot{\bar{a}}_{i j}^{l}\right]$ as interval numbers; and $\left(\dot{a}_{i j}^{l}, \hat{b}_{i j}^{l}, \hat{c}_{i j}^{l}\right)$ as TFNs. Since these attributes are naturally different and they may affect the problem solution unequally; therefore, it would be to weigh them according to the experts' opinions. The weights of attributes given by each decision maker $\left(e_{i j}^{l}\right)(l \in P)$ illustrated as $W_{i j}^{l}=$ $\left(W_{1 j}^{l}, W_{2 j}^{l}, \ldots W_{n j}^{l}\right), \quad \sum_{i=1}^{n} W_{i j}^{l}=1$ and $0 \leq W_{i j}^{l} \leq 1$. This section describes the proposed method for solving the considered heterogeneous decision-making problem. Summarily, the heterogeneous DM problem structure is proposed to prioritize a set of alternatives according to a set of criteria, when each criterion has a different type. Here, the research process enters the HWASPAS phases. The following steps indicate the road map of the remainder of the paper through the HWASPAS method to select the location for entrepreneurs entities.

Step 1. Development of Decision Matrix. in the first step, the problem is formalized by constructing the decision matrix. This step requires identifying decision alternatives, decision criteria, and forming an expert group of decision-makers. Then, each decision-maker completes his/ her decision matrix. Eq. (2) illustrates the constructed decision matrix by expert $l$.

$$
X^{l}=\left[\begin{array}{cccc}
x_{11}^{l} & x_{12}^{l} & \cdots & x_{1 n}^{l} \\
x_{21}^{l} & x_{22}^{l} & \cdots & x_{2 n}^{l} \\
\vdots & \vdots & \ddots & \vdots \\
x_{m 1}^{l} & x_{m 2}^{l} & \cdots & x_{m n}^{l}
\end{array}\right]
$$

Step2. Attributes' weights calculation. In the second step, criteria weight vector $W$ is computed. A planetary of methods can be used to determine this weight vector, e.g. Entropybased method, CRITIC, SWARA (Keršulienè et al., 2010), pairwise comparison-based methods, best-worst method (BWM) (Rezaei, 2015) BWM-I (Pamucar et al. 2020), Simultaneous Evaluation of Criteria and Alternatives (SECA) (Keshavarz Ghorabaee et al. 2018), etc. In this study, the weights are calculated through pairwise comparisons. In many multi-criteria problems, the analytical hierarchical process (AHP) is the most widely used method, using pairwise comparison judgment which is a useful tool to estimate the relative weights on decision elements like criteria matrix (Song and Kang, 2016; Cavallo and D’Apuzzo, 2016; Razavi Hajiagha et al., 2015b).

Step 3. Aggregation. Since several experts imply their opinion, the aggregation matrix is an important part of group decision-making (Yaping, 2016; Beheshti et al., 2016). In this section, concerning each type of number, the appropriate aggregation method is employed. Suppose that $\lambda=\left(\lambda_{1}, \lambda_{2}, \ldots, \lambda_{p}\right)$ is the weight vector of experts. For criteria that are measured using real numbers, if the considered criterion is related to a measurable and exact feature, e.g. declared cost, no aggregation is required. Otherwise, the weighted averaging operator is used to find the aggregated value of the criterion. Suppose a real criterion $c_{j}, j \in$ $\left\{1,2, \ldots, k_{1}\right\}$ that different expert evaluated it for a given alternative $a_{i}, i \in\{1,2, \ldots, m\}$. The evaluated values are $\left\{x_{i j}^{1}, x_{i j}^{2}, \ldots, x_{i j}^{p}\right\}$. These values are aggregated as equation (3).

$$
\dot{x}_{i j}=\frac{\sum_{l=1}^{p} \lambda_{l} x_{i j}^{l}}{\sum_{l=1}^{p} \lambda_{l}}
$$

For the set of interval criteria, the aggregated value of the criterion $c_{j}, j \in\left\{k_{1}+1, k_{1}+\right.$ $\left.2, \ldots, k_{2}\right\}$ for a given alternative $a_{i}, i \in\{1,2, \ldots, m\}$ that are evaluated by experts as $\left\{x_{i j}^{1}, x_{i j}^{2}, \ldots, x_{i j}^{p}\right\}$, where $x_{i j}=\left[\underline{a}_{i j}, \bar{a}_{i j}\right]$, can be calculated as equation (4) 


$$
x_{i j}=\left[\underline{\dot{a}}_{i j}, \dot{\bar{a}}_{i j}\right]=\frac{\sum_{l=1}^{p} \lambda_{l} x_{i j}^{l}}{\sum_{l=1}^{p} \lambda_{l}}=\frac{\sum_{l=1}^{p} \lambda_{l}\left[\underline{\dot{a}}_{i j}^{l} \dot{\bar{a}}_{i j}^{l}\right]}{\sum_{l=1}^{p} \lambda_{l}}=\frac{\left[\sum_{l=1}^{p} \lambda_{l} \underline{\dot{a}}_{i j}^{l}, \sum_{l=1}^{p} \lambda_{l} \dot{\bar{a}}_{i j}^{l}\right]}{\sum_{l=1}^{p} \lambda_{l}}
$$

In the case of TFNs, i.e. criteria set $\mathrm{C}_{3}$, for a criterion $c_{j}, j \in\left\{k_{2}+1, k_{2}+2, \ldots, k_{3}\right\}$ over an alternative $a_{i}, i \in\{1,2, \ldots, m\}$ where experts expressed their evaluations as $x_{i j}^{l}=$ $\left(\hat{a}_{i j}^{l}, \hat{b}_{i j}^{l}, \hat{c}_{i j}^{l}\right)$, the aggregated value is obtained as follows.

$x_{i j}=\left(\dot{a}_{i j}, \hat{b}_{i j}, \dot{c}_{i j}\right)=\frac{\sum_{l=1}^{p} \lambda_{l} x_{i j}^{l}}{\sum_{l=1}^{p} \lambda_{l}}=\frac{\sum_{l=1}^{p} \lambda_{l}\left(\dot{a}_{i j}^{l}, \dot{b}_{i j}^{l}, \dot{c}_{i j}^{l}\right)}{\sum_{l=1}^{p} \lambda_{l}}=\frac{\left(\sum_{l=1}^{p} \lambda_{l} \dot{a}_{i j}^{l}, \Sigma_{l=1}^{p} \lambda_{l} \dot{b}_{i j}^{l} \Sigma_{l=1}^{p} \lambda_{l} \dot{c}_{i j}^{l}\right)}{\sum_{l=1}^{p} \lambda_{l}}$

Finally, to aggregate intuitionistic fuzzy numbers, the intuitionistic fuzzy weighted averaging (IFWA) operator is used, as illustrated in Eq. (6) (Wang and Liu, 2012).

$I F W A=\left\langle\dot{\mu}_{i j}, \dot{v}_{i j}\right\rangle=\left\langle 1-\prod_{l=1}^{p}\left(1-\dot{\mu}_{i j}^{l}\right)^{\lambda_{l}}, \prod_{l=1}^{p} \dot{v}_{i j}^{l} \lambda_{l}\right\rangle$

Step 4. Normalization. According to various measurement scales in MADM problems, i.e. different criteria, $x_{i j}$, have different scales, the normalization is required to harmonize measurement scales so that further mathematical computations being possible. In this paper, the following normalization rules are used in the WASPAS method, inspiring from its original form as proposed by (Zavadskas et al., 2012) and (Chakraborty et al., 2015). This method is used for buildings in Lithuania's rural areas with IVIF numbers (Zavadskas et al., 2014; Hajiagha et al., 2015a). The normalization process for each type of number follows the appropriate transformations; accordingly, fuzzy numbers are normalized based on (Turskis et al., 2019) and intuitionistic fuzzy numbers are normalized according to (Schitea, et al., 2019), and the interval numbers follow (Zavadskas et al., 2015).

Step 4-1) In case the $\max _{i} \dot{x}_{i j}$ is preferable (benefit criteria), normalization is as follows.

$$
\bar{x}_{i j}=\left\{\begin{array}{lr}
\bar{x}_{i j}=\dot{x}_{i j} / \max _{i} \dot{x}_{i j} & \left(j \in C_{1}^{b}\right) \\
{\left[\underline{a}_{i j}, \bar{a}_{i j}\right]=\left[\underline{a}_{i j} / \max _{i} \dot{\bar{a}}_{i j}, \dot{\bar{a}}_{i j} / \max _{i} \dot{\bar{a}}_{i j}\right]} & \left(j \in C_{2}^{b}\right) \\
\left(a_{i j}, b_{i j}, c_{i j}\right)=\left(\dot{a}_{i j} / \max _{i} \dot{c}_{i j}, \hat{b}_{i j} / \max _{i} \dot{c}_{i j}, \dot{c}_{i j} / \max _{i} \dot{c}_{i j}\right) & \left(j \in C_{3}^{b}\right) \\
\left\langle\mu_{i j}, v_{i j}\right\rangle=\left\langle\dot{\mu}_{i j}, \hat{v}_{i j}\right\rangle & \left(j \in C_{4}^{b}\right)
\end{array}\right.
$$

Step 4-2) If the $\min _{i} \dot{x}_{i j}$ is preferable (cost criteria), normalization is as follows.

$$
\bar{x}_{i j}=\left\{\begin{array}{lr}
\bar{x}_{i j}=1-\dot{x}_{i j} / \max _{i} \dot{x}_{i j} & \left(j \in C_{1}^{c}\right) \\
{\left[\underline{a}_{i j}, \bar{a}_{i j}\right]=\left[1-\dot{\bar{a}}_{i j} / \max _{i} \dot{\bar{a}}_{i j}, 1-\underline{a}_{i j} / \max _{i} \dot{\bar{a}}_{i j}\right]} & \left(j \in C_{2}^{c}\right) \\
\left(a_{i j}, b_{i j}, c_{i j}\right)=\left(1-\dot{c}_{i j} / \max _{i} \dot{c}_{i j}, 1-\dot{b}_{i j} / \max _{i} \dot{c}_{i j}, 1-\dot{a}_{i j} / \max _{i} \dot{c}_{i j}\right) & \left(j \in C_{3}^{c}\right) \\
\left\langle\mu_{i j}, v_{i j}\right\rangle=\left\langle\dot{v}_{i j}, \mu_{i j}\right\rangle & \left(j \in C_{4}^{b}\right)
\end{array}\right.
$$

(Yu et al., 2018; Raj Mishra et al., 2018).

Step 5. Computation of weighted sum model (WSM) and weighted product model (WPM). After normalizing the decision matrix, the next step is to use the WASPAS method to determine the alternative score. The WASPAS method is a combination of the weighted sum method (WSM) and the weighted product method (WPM). The first part of the method, i.e. WSM, includes finding the weighted sum score $Q_{i}, i=1,2, \ldots, m$ for each alternative as equation (9). 


$$
Q_{i}=\sum_{j=1}^{n} w_{j} \bar{x}_{i j}
$$

Considering the heterogeneous nature of the proposed method, the score $Q_{i}$ is a heterogeneous score with the following form.

$Q_{i}=\sum_{j=1}^{n} w_{j} \bar{x}_{i j}=\sum_{j \in C_{1}} w_{j} \bar{x}_{i j}+\sum_{j \in C_{2}} w_{j} \bar{x}_{i j}+\sum_{j \in C_{3}} w_{j} \bar{x}_{i j}+\sum_{j \in C_{4}} w_{j} \bar{x}_{i j}$

The first term of the right-hand side of the above equation is calculated straightforwardly. The second term is computed using the scalar multiplication and sum of interval numbers (Zavadskas et al., 2015) as follows.

$$
\sum_{j \in C_{2}} w_{j} \bar{x}_{i j}=\left[\sum_{j \in C_{2}} w_{j} \underline{a}_{i j}, \sum_{j \in C_{2}} w_{j} \bar{a}_{i j}\right]
$$

For TFNs, the third term of the right-hand side of Eq. (9) is equal to equation (12).

$$
\sum_{j \in C_{3}} w_{j} \bar{x}_{i j}=\left(\sum_{j \in C_{3}} w_{j} a_{i j}, \sum_{j \in C_{3}} w_{j} b_{i j}, \sum_{j \in C_{3}} w_{j} c_{i j}\right)
$$

Eventually, for intuitionistic fuzzy numbers, WSM is calculated as follows (Schitea et al., 2019):

$\sum_{j \in C_{4}} w_{j} \bar{x}_{i j}=\sum_{j \in C_{4}} w_{j}\left\langle\mu_{i j}, v_{i j}\right\rangle=\left\langle\mu_{s i}, v_{s i}\right\rangle$

The above equation is obtained by applying the scalar multiplication and IFNs addition operators. Therefore, the final $Q_{i}$ is a combined number. To find a unique solution, according to (Zavadskas et al., 2012; Zavadskas et al., 2015; Turskis et al., 2019), and (Zhang et al., 2012), the weighted sum score is calculated as follows.

$Q_{i}=\sum_{j \in C_{1}} w_{j} \bar{x}_{i j}+\frac{1}{2} \sum_{j \in C_{2}} w_{j}\left(\underline{a}_{i j}+\bar{a}_{i j}\right)+\frac{1}{3} \sum_{j \in C_{3}} w_{j}\left(a_{i j}+b_{i j}+c_{i j}\right)+\frac{1}{2} \frac{1-v_{s i}}{2-\mu_{s i}-v_{s i}}$

The second part of the WASPAS method is to calculate a weighted product score for each alternative, called $P_{i}, i=1,2, \ldots, m$, which is defined as follows.

$$
P_{i}=\left(\prod_{j=1}^{n} \bar{x}_{i j} w_{j}\right)^{1 / \Sigma_{j=1}^{n} w_{j}}=\left(\prod_{j=1}^{n} \bar{x}_{i j}{ }^{w_{j}}\right)
$$

That the lase equality holds since $\sum_{j=1}^{n} w_{j}=1$. Similarly, because different criteria are measured with different types, the above relation needs to be adjusted. Therefore, the equation is rewritten as follows.

$$
P_{i}=\left(\prod_{j=1}^{n} \bar{x}_{i j}{ }^{w_{j}}\right)=\left(\prod_{j \in C_{1}} \bar{x}_{i j}{ }^{w_{j}}\right)\left(\prod_{j \in C_{2}} \bar{x}_{i j}{ }^{w_{j}}\right)\left(\prod_{j \in C_{3}} \bar{x}_{i j}{ }^{w_{j}}\right)\left(\prod_{j \in C_{4}} \bar{x}_{i j}{ }^{w_{j}}\right)
$$

The above equation is elaborated according to the data type. For the first term of the righthand side, i.e. for real numbers, the weighted product score is computed straightforwardly. The second term of the right-hand side, which is the weighted product of interval numbers, is obtained as follows (Zavadskas et al., 2015).

$$
\prod_{j \in C_{2}} \bar{x}_{i j}{ }^{w_{j}}=\prod_{j \in C_{2}} \frac{1}{2}\left(\underline{a}_{i j}{ }^{w_{j}}+\bar{a}_{i j}{ }^{w_{j}}\right)
$$

The weighted product score of the third term, related to triangular fuzzy criteria is determined as (Turskis et al., 2019):

$\prod_{j \in C_{3}} \bar{x}_{i j}{ }^{w_{j}}=\left(p_{i 1}, p_{i 2}, p_{i 3}\right)=\left(\left(\prod_{j \in C_{3}} a_{i j}\right)^{\sum_{j \in C_{3}} w_{j}},\left(\prod_{j \in C_{3}} b_{i j}\right)^{\sum_{j \in C_{3}} w_{j}},\left(\prod_{j \in C_{3}} c_{i j}\right)^{\sum_{j \in C_{3}} w_{j}}\right)$

For intuitionistic fuzzy numbers, the weighted sum score is calculated by applying the power and multiplication operations of IFNs. By applying these operators, an intuitionistic fuzzy weighted product score $\left\langle\mu_{p i}, v_{p i}\right\rangle$ is obtained. By aggregating these results, the final score is a combined number. To achieve a single score for each alternative, using the transformation operators the $P_{i}$ the score is obtained as follows. 


$$
P_{i}=\left(\prod_{j \in C_{1}} \bar{x}_{i j}{ }^{w_{j}}\right)\left(\prod_{j \in C_{2}} \frac{1}{2}\left(\underline{a}_{i j}{ }^{w_{j}}+\bar{a}_{i j}{ }^{w_{j}}\right)\right)\left(\frac{1}{3}\left(p_{i 1}+p_{i 2}+p_{i 3}\right)\right)\left(\frac{1}{2} \frac{1-v_{p i}}{2-\mu_{p i}-v_{p i}}\right)
$$

Step 6. Calculation of total relative importance for each alternative. Computing the weighted sum score $Q_{i}$ and the weighted product score $P_{i}$ for any alternative, the weighted aggregated sum product assessment (WASPAS) score is calculated as follows.

$$
K_{i}=\lambda Q_{i}+(1-\lambda) P_{i} \lambda \in[0,1]
$$

This is calculated through a different type of equation regarding the nature of numbers as mentioned above. There are some methods to calculate $\lambda$ (Chakraborty et al., 2015) presented as follows.

$$
\lambda=\frac{\sigma^{2}\left(P_{i}\right)}{\sigma^{2}\left(Q_{i}\right)+\sigma^{2}\left(P_{i}\right)}
$$

Which $\sigma^{2}\left(Q_{i}\right)$ and $\sigma^{2}\left(P_{i}\right)$ might be obtained using the given Eqs as bellow.

$$
\begin{aligned}
\sigma^{2}\left(Q_{i}\right) & =\sum_{j=1}^{n} w_{j}^{2} \sigma^{2}\left(\bar{x}_{i j}\right) \\
\sigma^{2}\left(P_{i}\right) & =\sum_{j=1}^{n}\left[\frac{\prod_{j=1}^{n}\left(\bar{x}_{i j}\right)^{w_{j}} w_{j}}{\left(\bar{x}_{i j}\right)^{w_{j}}\left(\bar{x}_{i j}\right)^{1-w_{j}}}\right]^{2} \sigma^{2}\left(\bar{x}_{i j}\right)
\end{aligned}
$$

Note that $\bar{x}_{i j}$ is the normalized value of $x_{i j}$ and $w_{j}$ indicates the weight of the $j^{\text {th }}$ criteria. Moreover, $\sigma^{2}$ of the normalized initial values can be obtained through Eq (24).

$$
\sigma^{2}\left(\bar{x}_{i j}\right)=\left(0.05 \bar{x}_{i j}\right)^{2}
$$

However, most of the time $\lambda$ is assumed 0.5 (Saparauskas et al., 2011). Finally, alternatives are ranked according to the descending order of the obtained $K_{i}, i=1,2, \ldots, m$ values.

\section{Case study and Results}

In this part, the proposed methodology is employed in a real-world case to solve the decisionmaking problem for startup location selection. NAD Co. is a pharmaceutical startup which is founded to develop an anti-bacterial medicine using herbal products. This drug is in the form of topical ointment or gel. Some kinds of herbal products are probed to have a positive effect as Anti-bacterial and can be used as the solution for the treatment of bacterial infection (The type of infection is not used to keep the information confidential). As the developed formulation is rare and the application is limited in Iran, NAD is considered a knowledgebased pharmaceutical startup to develop this application. NAD Co is launched in 2019 and its core includes two biologists who manage the managerial and supportive activities; and a pharmacist who is casually required for technical procedures and operational processes. This team is supported by a management and marketing consultant team that facilitates the business progress and accelerates the process of product entry into the market. The managers decided to locate the central office in one of the STPs for the incubation stage and outsource the production. They also aim to develop new applications of similar products using the same raw materials. It may need access to market and homogenous neighbors and strategic partners. In this regard, the paper is developed on the pharmaceutical startup location problem in STPs as a case study. To select the most appropriate STP to locate the NAD Co, some data is required to prioritize the technology parks considering the company field and maturity. For this purpose, the effective elements of the location problem should be investigated. 
Screening. To find, select, and analyze these factors, the research team needs to determine criteria and obtain data. Initially, the criteria are reviewed in research studies. Then the list of 24 criteria is illustrated in table 2 that seem extra for decision making. They should be refined by international entrepreneurs opinions.

\section{$\underline{\text { Insert Table } 2}$}

This survey is performed based on experts opinions. Considering the accessibility to related experts and coordinating them easily to set a specific time for the meeting, the survey is performed through the 2-round Delphi method. In this regard, the research team established a panel of experts under managers' supervision and then at the first round distributed the questionnaires among them to receive their opinions about affective factors on central office location. The first round of the Delphi method consisted of 15 well-known and proficient infectious disease specialists and pharmacists around Tehran. They all held $\mathrm{PhD}$ and were ranked first or second in their field of expertise based on the annual list of Tehran specialists report. They had more than 10 years of experience and were located in Tehran. As they worked as referees for the Iranian medical and pharmaceutical innovation ecosystem, all experts were familiar with STPs circumstances and their support and incentive activities. The questionnaire was distributed by the representative of the research team. They implied their opinion in their office or clinic. In the second round, their opinions were gathered and analyzed by the research team, and then the results lead to developing the second-round questionnaire. In the second round of Delphi via modified questionnaire, the panel was asked to answer and revise the factors to improve the situations affecting the pharmaceutical startup location. Eventually, the factors were selected as follows and can be used to prioritize the STPs in this problem. The results include 10 criteria that seem to influence the startup location problem in the case of pharmacy. There are 8 STPs in Tehran (studied territory) which NAD Co. managers intended to prioritize including (1) Modares, (2) Tehran, (3) Azad University, (4) the Iran University of Medical, (5) Shahid Beheshti, (6) Pardis Technology Park (with a long destination to center), (7) Sharif and (8) National Park of soft technology and cultural industries. Their location is illustrated in Figure 2.

\section{$\underline{\text { Insert Figure } 2}$}

\section{$\underline{\text { Insert Table } 3}$}

Data gathering. Now, the managers need to decide where to locate their central office according to the list of available location alternatives concerning 10 decision-making criteria. For this purpose, the research team needs to determine the measure of these different criteria, especially user-friendly measures for respondents to imply their opinion with at least limitations and complexity. These criteria will be used to make the decision matrix with Heterogeneous nature. These criteria are expressed by different types of numbers as triangular fuzzy numbers (TFNs), real numbers; interval numbers (INNs); fuzzy numbers, and intuitionistic fuzzy numbers (IFNs) described in Table 4.

\section{Insert Table 4}

The data for criteria 1 and 7 were about rent and subsidiary costs which varied in a certain interval. The data for criteria 4 was a real number, and data for criteria 3 was obtained by counting the homogeneous startups in STPs that were varied in an interval. The nature of criteria $2,5,6$, and 8 were subjective and the experts should use triangular fuzzy numbers. For criteria 9 and 10, they could use the linguistic variables of Table 5 to indicate their opinion. 
HWASPAS. The 15 experts established three groups for decision-making. Each group including 5 members of the mentioned specialist gathered and tried to find the deterministic and nondeterministic data and complete a single decision matrix for their group. As each group of experts expressed their opinion about attributes, the data of Tehran STPs regarding these 10 attributes are illustrated in 3 decision matrices as presented in Table 5.

\section{$\underline{\text { Insert Table } 5}$}

Then, the weights of these attributes should be calculated through the AHP method which has been determined and is illustrated in Table 6 .

\section{$\underline{\text { Insert Table } 6}$}

In this part to reach consensus, the authors must aggregate expert's matrices and make a single matrix to calculate the ranks of alternatives concerning attributes. The aggregation is performed based on appropriate equations related to each type of number. The aggregated matrix is illustrated in Table 7.

\section{Insert Table 7}

For TFNs and interval numbers, the aggregated numbers are obtained through the mean equation as mentioned in the present step. Intuitionistic fuzzy numbers are aggregated concerning Eq (6). To harmonize the numbers from different types, various equations are proposed for normalization. Based on the nature of attributes two types of normalization Eqs (7), (8) are proposed for benefit or cost preference. Table 8 indicates the normalized values.

\section{$\underline{\text { Insert Table } 8}$}

When the normalized matrix is prepared, the next step computes WASPAS method values as a weighted sum model (WSM) and weighted product model (WPM) to evaluate alternatives regard attributes. Here, the WSM values for each type of attribute are calculated through Eqs. (11) - (13), and to find the unique solution score, Eq. (14) is employed. Moreover, the WPM values for each type of attribute are calculated through Eqs. (17) - (18) and to find the unique solution score Eq. (19). Finally, the total relative importance for each alternative $\left(k_{i}\right)$ is calculated through Eq. (20) along with the rank of alternatives are presented in Table 9.

\section{$\underline{\text { Insert Table } 9}$}

According to Table 9, the ranking indicates that Tehran STP is the most preferred location for NAD pharmaceutical startup and Sharif STP is the second priority for this startup to locate. The other priorities are ranked as indicated in Table 9 based on 10 attributes and various types of numbers and Azad STP is the last priority for pharmaceutical startup location which seems rational due to high values in cost criteria and low values in other criteria and Pardis Park stands on 7th step due to the park distance from Tehran (center and capital) considering the importance of interactions and accessibility of pharmaceutical corporates for fast reactions. To analyze the sensitivity of the results, according to Eq. (20), the WASPAS score is calculated for different values of $\lambda$. The results are shown in Table 10.

\section{$\underline{\text { Insert Table } 10}$}


Figure 3 illustrates the score of alternatives obtained in different values of $\lambda$. As can be seen, a stable pattern can be drawn from the figure on the alternatives rank. Therefore, the stability of the results can be accepted.

\section{Insert Figure 3}

Here, to compare the opinion of expert groups with final aggregated results, the problem is solved separately for each group using HWASPAS. Then, the obtained ranks of alternatives in each group are matched with the aggregated ranking. Figure 4 shows the homogeneity of individual groups with aggregated results.

\section{$\underline{\text { Insert Figure } 4}$}

As can be seen, the opinion of the first group of experts differs more than two other groups. Given to stability of ranks in Figure 4 and due to the lack of the same pattern for agreeing or disagree between groups, the aggregated WASPAS matrix seems reasonable and is acceptable for NAD Co. managers.

To validate the results obtained by the proposed method, the considered problem was solved using popular methods of handling heterogeneous decision-making methods. To this aim, the problem is solved using the heterogeneous qualitative flexible multiple (QUALIFLEX) method (Liang et al. 2020), heterogeneous TOPSIS method (Memari et al. 2019), and heterogeneous modular TOPSIS method (Gao and Li 2019). The results are shown in Table 11 .

\section{$\underline{\text { Insert Table } 11}$}

The Kendall's W for the compared methods was evaluated as more than $89 \%$ that illustrates a great similarity of the proposed method with other popular methods. Spearman's rank correlation measure was used also to compare the results. To this aim, Figure 5 illustrates the correlation of the rankings by different methods.

\section{Insert Figure 5}

A significant correlation, at least $90 \%$, is obtained between the proposed method and two other methods. However, the correlation among the proposed method with modular TOPSIS is insignificant, while it is approximated as about $60 \%$. Notably, the modular TOPSIS method illustrates the least correlation with other methods. The comparison with previous heterogeneous methods illustrates an acceptable performance for the proposed method.

\section{Implication and Discussion}

Startups try to operate based on shared resources which can be extended internationally. In emerging economies such as Iran, drugs are usually produced by domestic pharmaceutical companies; therefore, selecting the most appropriate location for the central office of pharmaceutical startups leads to positive effects on company performance to provide more efficient production operation with more economical and feasible expenditures, and can improve the country's health and drug system. Pharmaceutical startups need materials and knowledge as two important resources for operation. Therefore, these startups need to accommodate in appropriate locations to reach them easily. This concept necessitates the 
startup to make the most optimal decision to select its location considering various and probably conflicting criteria.

Theoretically, since location selection is an important decision for startups, it should be performed accurately and carefully by using appropriate tools and methods. According to the literature review, there are rarely location selection problems solved by MADM methods which are proved to be the most suitable tools to evaluate and rank alternatives based on various types and conflicting criteria. The review illustrates that studies are based on empirical studies, regression, and testing hypotheses; they are subjective and based on people's judgments. However, in this study, the criteria are extracted through Delphi rounds among specialists as a reliable and popular method to determine criteria and their weights. The determining criteria are used as decision attributes; their nature is specified as cost or benefit. Then, the alternatives are selected among available STPs and listed as decision matrix alternatives. The alternatives are ranked regarding the criteria based on some real numbers or some linguistic variables. Also, the present study considers different types of numbers simultaneously and evaluates the alternatives based on heterogeneous MADM methods. The heterogeneous numbers help decision-makers to use various types of statements, real numbers, and linguistic variables to imply their opinion. In this way, there is no pressure on decision-makers to imply accurate data and information to make the most optimal decision. This seems more precise and applicable than empirical studies. Then, the data of alternatives are gathered regarding attributes with different types of numbers to complete the decision matrix.

On the other hand, heterogeneous WASPAS is employed to solve the problem. It should be considered that the main advantage of WASPAS goes back to its high degree of reliability (Hashemnkhani Zolfani et al., 2013). In this study, three groups of experts who participated in the Delphi technique completed the decision matrix; thus, the matrices should be aggregated to achieve one decision matrix to solve the problem. Eqs. (4)-(6) were used for interval values, TFNs, and intuitionistic fuzzy variables respectively to reach the final aggregated matrix. Then the matrix values should be normalized to harmonize measurement scales so that further mathematical computations being possible. Normalization depends on the cost or benefit nature of the criteria to use Eq. (7) or (8). In the next step, the "weighted sum model (WSM) are calculated for alternatives; each type of variable is calculated based on suitable equations (11)-(13) and finally, the Eq. (14) is employed. Then, the "weighted product model" (WPM) is calculated using Eq. (16)-(18) and the final value is obtained by Eq. (19). The final step includes the calculation of total relative importance for each alternative (Eq. (20)) and ranking them according to these scores.

As mentioned previously, there are many studies on location and startups; nonetheless, the majority concentrate on geographical dimensions and cost-oriented matters. While this paper focuses on several different aspects to compare science and technology parks for startup's location. Therefore, this study may guide the less experienced startup managers to decide on central office location. Practically, the startup's managers learn how to pay attention to different criteria and take a precise trade-off among the expenditure pillars including location selection that costs significantly especially in the early stage. They start trusting on managerial calculations and their results while they experience the benefit from locating in STP, by using grants, memorandums of understanding with organizations, available infrastructural services, etc. 
Policymaking. As startups try to improve the business situations by using shared resources, they have no remarkable assets and resources at the initial steps; hence, they should save the resources and utilize them productively. Location selection is one costing and timeconsuming process for any corporation's figuration; it should be managed through logical procedure and decisions. The decision based on one feature or criteria such as cost may lead to bias in results and neglect some other effective factors like access to market, incubators, managerial consultant supports, close to users, etc. which can accelerate the startup's success progress. In this regard, this paper suggests the startups and SME managers to used comprehensive features of the location selection to find the most appropriate STPs to achieve these supports and prevent losing other accommodation opportunities carelessly. The results based on heterogeneous WASPAS indicate that Tehran STP stands in the first place, however, if the decision was made based on single criteria like cost, some other STPs could be preferable, and many managers would lose this choice. The other facilities, communications, infrastructures, homogeneity of other startups, shared resources, accelerative supports, etc. are considered as well as a cost factor and changed the bias decision's results. Therefore, the authors believe that the combination of the Delphi method and heterogeneous WASPAS can lead to reliable results for the startup's location selection problem comprehensively.

\section{Conclusion}

Given the rare opportunities for international startups to succeed, the location selection issue seems important to achieve these resources quickly and efficiently while locating in incubator centers and hubs. Recent efforts to establish STPs have provided the chance to receive and share technical knowledge, business guidance, and some free mentorship and similar services. This paper aims to solve a heterogeneous MADM problem through the WASPAS method which is a simple and capable mathematical model and provides precise results and is accepted to solve MADM problems efficiently (Chakraborty et al., 2015). The main advantage of the WASPAS method over other MADM methods is that it can identify alternative rankings through optimal parameter combinations, minimize personal judgments (Hashemkhani Zolfani et al., 2013), and provide an effective expert perspective (Stojić et al., 2018). This method is not affected by alternatives changes and is resistant to rank reversal properties (Chakraborty and Zavadskas, 2014). Since the location selection is crucially important for startups, it is necessary to find the most appropriate location to place the central office of the pharmaceutical corporations to easy access to research laboratories, academic researchers, common and rare specific resources, and financial and moral facilities to participate in related events to exchange information and transfer technology. On the other hand, it is accepted in STPs, and incubator centers are obviously difficult and due to limited seats there, this acceptance is rarely achieved. Therefore, startups should utilize opportunity optimally and try to compare these STPs and select the most suitable place to locate and obtain scarce resources to produce value-added efficiently.

Accordingly, the startup needs to compare the STPs based on efficient, effective, and related factors to reduce the undesired effects caused by losing the other opportunities. These factors or attributes are extracted through the Delphi method which is performed among 15 experts. They selected 10 attributes that affect the decision-making problem on the location of the pharmaceutical startup and reached a consensus on their weights using pairwise comparison. Then three senior managers of the startup implied their opinion about 8 STPs regard to these 10 attributes. In this regard, they were allowed to use different types of numbers to transfer their opinion. Then, the WASPAS method was used to calculate the score of each alternative and rank them to place the NAD startup successfully. The pressure on decision-makers to 
represent the precise and accurate viewpoint; however, in real decision situations, inaccurate data, time shortage, lack of information and other factors lead to approximate responses. In this regard, the heterogeneous numbers provide the decision-makers with the opportunity to use wide types of statements, real numbers, and linguistic variables to express their opinion. Therefore, in this paper, the decision-makers exploited the heterogeneous numbers and expressed their viewpoint to rank the STPs and locate the office of the NAD startup. The calculations for each type of number are based on related equations proposed by various researchers.

As the literature review indicates very rare researches investigate startup location selection using MADM methods, however; conflict criteria are important to make the most optimal decision to locate the startup. Since the decision-makers may tend to imply their opinion through linguistic variables; and due to imprecise and non-accurate data, more often they prefer to use non-deterministic numbers. Therefore, the present research has a novelty to consider conflict criteria through heterogeneous MADM methods under uncertainty conditions. For further researches, it is suggested to calculate the weights of heterogeneous numbers for group decision-making; however, in this paper, the weights of attributes were calculated through pairwise comparison of real numbers. Moreover, a combination of MADM methods with heterogeneous numbers can be extended to compare the results and make the most appropriate decision. Moreover, a higher number of experts and other organizations can be included and compared with the results of this research. Eventually, performance evaluation of pharmaceutical startups based upon the extracted criteria should be investigated to compare with the results of this study.

\section{References}

Akcan, S. and Güldeş, M., (2019), Integrated Multicriteria Decision-Making Methods to Solve Supplier Selection Problem: A Case Study in a Hospital. Journal of healthcare engineering, p. 10.

Abramovsky, L. and Simpson, H., (2011), Geographic proximity and firm-university innovation linkages: evidence from Great Britain. J. Econ. Geogr, Vol. 11, p. 949-977.

Aditi, Kaul, A., Darbari, J. and Jha, P., (2020), A Fuzzy MCDM Model for Facility Location Evaluation Based on Quality of Life. In: Soft Computing for Problem Solving. Advances in Intelligent Systems and Computing. Singapore: Springer, pp. 687-697.

Afful-Dadzie, E., Oplatková, Z. and Beltran Prieto, L., (2017), Comparative State-of-the-Art Survey of Classical Fuzzy Set and Intuitionistic Fuzzy Sets in Multi-Criteria Decision Making. International Journal of Fuzzy Systems volume, 19(3), pp. 726-738.

Ak, M. and Acar, D., (2021), Selection of Humanitarian Supply Chain Warehouse Location: A Case Study Based on the MCDM Methodology. [Online].

Albahari, A., Barge-Gil, A., Pérez-Canto, S., and Modrego, A., (2016), The influence of Science and Technology Park characteristics on firms' innovation results. Papers in Regional Science, 97(2), p. 253-279.

Allen, T., (2016), The power of reciprocal knowledge-sharing relationships for startup success. Journal of Small Business and Enterprise Development, 23(3), p. 636-651.

Almeida, A., Afonso, Ó. and Rui Silva, M., (2020), Panacea or Illusion: An Empirical Analysis of European Science Parks in the Case of Follower Regions. Journal of Innovation Economics and Management, pp. 155194.

Atanassov, K., (1986), Intuitionistic fuzzy sets. Fuzzy Sets and Systems, 20(1), pp. 87-96.

Athawale, V.M., Chatterjee, P. and Chakraborty, S., (2012), Decision making for facility location selection using PROMETHEE II method. International Journal of Industrial and Systems Engineering, 11((1/2)),

Aydin, N. and Seker, S., (2021), Determining the location of isolation hospitals for COVID-19 via Delphi-based MCDM method. International Journal of Intelligent Systems.

Baykasoğlu, A. and Gölcük, İ., (2019), Revisiting ranking accuracy within WASPAS method. Kybernetes, 49(3), pp. 885-895. 
Bede, B., (2013), Extensions of Fuzzy Set Theory. In: Mathematics of Fuzzy Sets and Fuzzy Logic. Berlin, Heidelberg: Springer, pp. 193-199.

Beheshti, M., Mahdiraji, H. and Zavadskas, E., (2016), Strategy portfolio optimisation: A copras g-modm hybrid approach. Transformations in Business and Economics, 15(3C), pp. 500-519.

Bignami, F., Mattsson, P. and Hoekman, J., (2019), The importance of geographical distance to different types of R\&D collaboration in the pharmaceutical industry. Industry and Innovation, p. 1-25.

Brcic, R., Brodar, K. and Vugrinovic, A., (2010), Success factors for Science and Technology Parks in Croatia. s.1., University of Sarajevo, School of Economics and Business, Sarajevo.

Budak, A., Kaya, İ., Karaşan, A. and Erdoğan, M., (2020), Real-time location systems selection by using a fuzzy MCDM approach: An application in humanitarian relief logistics. Applied Soft Computing.

Cavallo, B. and D'Apuzzo, L., (2016), Ensuring reliability of the weighting vector: Weak consistent pairwise comparison matrices. Fuzzy sets and systems, Vol. 296, pp. 21-34.

Chakraborty, S., and Zavadskas, E.K. (2014), Applications of WASPAS method in manufacturing decision making. Informatica, 25(1), 1-20.

Chakraborty, S., Zavadskas, E. K. and Antucheviciene, J., (2015), Applications of waspas method as a multicriteria decision-making tool. Economic computation and economic cybernetics studies and research, Vol. 49, pp. 5-22.

Chen, C. and Hsiao, Y., (2013), The endogenous role of location choice in product innovations. Journal of World Business, 28(3), pp. 360-372.

Chen, H., Zeng, S., Yu, B. and Xue, H., (2019), Complementarity in Open Innovation and Corporate Strategy: The Moderating Effect of Ownership and Location Strategies. IEEE Transactions on Engineering Management, pp. 1-15.

Chin, C. T., Lin, C. T. and Huang, S. F., (2006), A fuzzy approach for supplier evaluation and selection in supply chain management, International Journal of Production Economics, 102(2), pp. 289-301.

Chowdhury, P. and Paul, S. K., (2020), Applications of MCDM methods in research on corporate sustainability: A systematic literature review. Management of Environmental Quality, 31(2), pp. 385-405.

Dohse, D. and Schnier, J., (2019), Location and Firm Performance. In: From Industrial Organization to Entrepreneurship. s.1.: Springer, Cham, pp. 307-317.

Ejegwa, P. and Onyeke, I., (2021), Intuitionistic fuzzy statistical correlation algorithm with applications to multicriteria-based decision-making processes. International Journal of Intelligent Systems, 36(3), pp. 13861407.

Ferreira, J., Fernandes, C., and Raposo, M., (2017), The Effects of Location on Firm Innovation Capacity. Journal of the Knowledge Economy, 8(1), pp. 77-96.

Gassmann, O. and Reepmeyer, G., (2005), Organizing Pharmaceutical Innovation: From Science-based Knowledge Creators to Drug-oriented Knowledge Brokers. Creativity and Innovation Management, 14(3), p. 233-245.

Gursel, A., (2014), Science and Technology Parks and University Collaborations. Periodicals of engineering and natural sciences, 2(2), pp. 35-40.

Hajiagha, S., Hashemi, S. and Mahdiraji, H., (2015a), Multi-period data envelopment analysis based on Chebyshev inequality bounds. Expert Systems with Applications, 42(21), pp. 7759-7767.

Hajiagha, S., Mahdiraji, H. and Hashemi, S., (2015b), Evolving a linear programming technique for MAGDM problems with interval-valued intuitionistic fuzzy information. Expert Systems with Applications, 42(23), pp. 9318-9325.

Hamdouch, A. and Moulaert, F., (2006), Knowledge Infrastructures, Innovation Dynamics and Knowledge Creation, Diffusion, Accumulation Processes: A Comparative Institutional Perspective. Special Issue: "The Knowledge Infrastructure: Analysis, Institutional Dynam. The European Journal of Social Science Research, Vol. 19, pp. 25-50.

Hansson, F., Husted, K., and Vestergaard, J., (2005), Second generation science parks: From structural holes jockeys to social capital catalysts of the knowledge society. Technovation, 25(9), p. 1039-1049.

Hashemkhani Zolfani, S. Aghdaie, M.H., Derakhti, A., Zavadskas, E.K., Varzandeh, M.H.M, (2013), "Decision making on business issues with foresight perspective; an application of new hybrid MCDM model in shopping mall locating", Expert Systems with Applications, 40, pp. 7111-7121. 
Hervas-Oliver, J. and Albors-Garrigos, J., (2014), Are technology gatekeepers renewing clusters? Understanding gatekeepers and their dynamics across cluster life cycles. Entrepreneurship and Regional Development, Vol. 26, pp. 431-452.

Hobbs, K., Link, A. and Scott, J., (2017), Science and technology parks: an annotated and analytical literature review. Journal of Technology Transfer, Vol. 42, p. 957-976.

Huang, K.F., Yu, C.M. J. and Seetoo, D.-H., (2012), Firm innovation in policy-driven parks and spontaneous clusters: the smaller firm the better?. The Journal of Technology Transfer, 37(5), p. 715-731.

Hussain, A., Chun, J. and Khan, M., (2021), A novel multicriteria decision making (MCDM) approach for precise decision making under a fuzzy environment. Soft Computing, 25(7), pp. 5645-5661.

Johansson, B. and Lööf, B., (2008), Innovation activities explained by firm attributes and location. Economics of Innovation and New Technology, Vol. 17, p. 533-552.

Kahraman, C., (2008), Multi-Criteria Decision Making Methods and Fuzzy Sets. In: Fuzzy Multi-Criteria Decision Making: Theory and Applications with Recent Developments. Boston: Springer, pp. 1-18.

Karaşan, A., Kaya, İ. and Erdoğan, M., (2018), Location selection of electric vehicle charging stations by using a fuzzy MCDM method: a case study in Turkey. Neural Computing and Applications.

Keršulienè, V., Zavadskas, E. K. and Turskis, Z., (2010), Selection of rational dispute resolution method by applying new step-wise weight assessment ration analysis (SWARA), Journal of Business Economics and Management, 11(2), pp. 243-258.

Keshavarz-Ghorabaee, M., Amiri, M., Zavadskas, E. K., Turskis, Z., and Antucheviciene, J. (2018), Simultaneous evaluation of criteria and alternatives (SECA) for multi-criteria decision-making. Informatica, Vol. 29, No. 2, pp. 265-280.

Kaloudis, A., and Svoboda, O. (2019), Quality of Government, stocks of innovation skills and level of economic activity in European regions. In Liberec economic forum 2019: proceedings of the 14th international conference. Technická univerzita v Liberci.

Klyucharev, G. A., Tyurina, I. O., and Neverov, A. V. (2017), the International experience of techno-parks in the Russian context.

Lai, H. and Shyu, J., (2005), A comparison of innovation capacity at science parks across the Taiwan Strait: the case of Zhangjiang High-Tech Park and Hsinchu Science-based Industrial Park. Technovation, 25(7), pp. 805813.

Lamperti, F., Mavilia, R. and Castellini, S., (2017), The role of Science Parks: a puzzle of growth, innovation and R\&D investments. Journal of Technology Transfer, Vol. 42, p. 158-183.

Lecuyer, C., (2006), Making Silicon Valley: Innovation and the Growth of High Tech. Cambridge, MA: MIT Press.

Link, A. and Scott, J., (2019), Geographic Proximity and Science Parks, s.1.: University of North Carolina at Greensboro.

Mardani, A., (2017), A systematic review and meta-Analysis of SWARA and WASPAS methods: Theory and applications with recent fuzzy developments. Applied Soft Computing, Vol. 57, pp. 265-292.

Mason, C. and Brown, R., (2014), Entrepreneurial ecosystems and growth-oriented entrepreneurship. Background paper prepared for the workshop organised by the OECD LEED Programme and the Dutch Ministry of Economic Affairs on Entrepreneurial Ecosystems and Growth-Oriented Entrepreneurship, Netherlands: The Hague.

McCann, B. and Folta, T., (2008), Location matters: Where we have been and where we might go in agglomeration research. Journal of Management, Vol 34, p. 532-565.

Mokhtarzadeh, N.G., Mahdiraji, H.A., Jafarpanah, I., Jafari-Sadeghi, V. and Cardinali, S., (2020), Investigating the impact of networking capability on firm innovation performance: using the resource-action-performance framework. Journal of Intellectual Capital.

Molina-Morales, F.X., García-Villaverde, P.M. and Parra-Requena, G., (2011), Geographical and cognitive proximity effects on innovation performance in SMEs: a way through knowledge acquisition. International Entrepreneurship and Management Journal, 10(2),

Morente-Molinera, J., (2020), A novel multi-criteria group decision-making method for heterogeneous and dynamic contexts using multi-granular fuzzy linguistic modelling and consensus measures. Information Fusion, Vol. 53, pp. 240-250.

Motohashi, K., (2013), The role of the science park in innovation performance of start-up firms: an empirical analysis of Tsinghua Science Park in Beijing. Asia Pacific Business Review, 19(4), p. 578-599. 
Pamučar, D., Ecer, F., Cirovic, G., and Arlasheedi, M. A. (2020), Application of improved best-worst method (BWM) in real-world problems. Mathematics, Vol. 8, No. 8, pp.1342.

Plotnikova, T. and Rake, B., (2013), Collaboration in pharmaceutical research: exploration of country-level determinants. Scientometrics, 98(2), p. 1173-1202.

Ponds, R., van Oort, F. and Frenken, K., (2010), Innovation, spillovers, and university-industry collaboration: an extended knowledge production function approach. J. Econ. Geogr, Vol. 10, p. 231-255.

Pugh, R., Soetanto, D. and Jack, S., (2021), Developing local entrepreneurial ecosystems through integrated learning initiatives: the Lancaster case. Small Business Economics, Vol. 56, p. 833-847.

Raj Mishra, A., Singh, R., and Motwani, D., (2018), Multi-criteria assessment of cellular mobile telephone service providers using intuitionistic fuzzy WASPAS method with similarity measures. Granular Computing, 1(8), pp. 1-19.

Ramirez-Nafarrate, A., Araz, O. and Fowler, J., (2021), Decision Assessment Algorithms for Location and Capacity Optimization under Resource Shortages. Decision Sciences, 52(1), pp. 142-181.

Razavi Hajiagha S.H., Ahmadzadeh Kandi N. (2021) A Hybrid Interval-Valued Intuitionistic Fuzzy Aggregation Operator-Based Algorithm for Team Member Selection of International Entrepreneurs. In: JafariSadeghi V., Amoozad Mahdiraji H., Dana LP. (eds) Empirical International Entrepreneurship. Contributions to Management Science. Springer, Cham.

Razavi Hajiagha, S., Hashemi, S. S., Zavadskas, E. K. and Akrami, H., (2012), Extensions of LINMAP model for multi-criteria decision making with grey numbers. Technological and Economic Development of Economy, pp. 636-650.

Razavi Hajiagha, S., Mahdiraji, H. and Hashemi, S., (2015), Determining weights of fuzzy attributes for multiattribute decision-making problems based on consensus of expert opinions. Technological and Economic Development of Economy, 21(5), pp. 738-755.

Rezaei, J. (2016), Best-worst multi-criteria decision-making method: Some properties and a linear model. Omega, Vol. 64, pp. 126-130.

Robaczewska, J., Vanhaverbeke, W. and Lorenz, A., (2019), Applying open innovation strategies in the context of a regional innovation ecosystem: The case of Janssen Pharmaceuticals. Global Transitions, Vol. 1, p. 120131.

Rothaermel, F. and Deeds, D., (2004), Exploration and exploitation alliances in biotechnology: a system of new product development. Strategic Management Journal, Vol. 25, p. 201-221.

Saparauskas, J., Zavadskas, E. K. and Turskis, Z., (2011), Selection of Facade's Alternatives of Commercial and Public Buildings Based on Multiple Criteria. s.1., s.n., pp. 189-203.

Schitea, D., (2019), Hydrogen mobility roll-up site selection using intuitionistic fuzzy sets based WASPAS, COPRAS, and EDAS. International Journal of Hydrogen Energy, 44(16), pp. 8585-8600.

Shi, Z., Lee, G. M. and Whinston, A., (2016), Toward a Better Measure of Business Proximity: Topic Modeling for Industry Intelligence. MIS Quarterly, 40(4), pp. 1035-1056.

Silva, D. S., (2019), Lean Startup, Agile Methodologies and Customer Development for business model innovation. International Journal of Entrepreneurial Behavior and Research.

Şimşek, K. and Yıldırım, N., (2016), Constraints to Open Innovation in Science and Technology Parks. Procedia - Social and Behavioral Sciences, Vol 235, p. 719-728.

Song, B. and Kang, S., (2016), A Method of Assigning Weights Using a Ranking and Nonhierarchy Comparison. Advances in Decision Sciences, pp. 1-10.

Squicciarini, M., (2008), Science parks' tenants versus out-of-park firms: Who innovates more? A duration model. Journal of Technology Transfer, 33(1), p. 45-71.

Stefanidis, D., Korndorffer, J. and Sweet, R., (2019), Comprehensive Healthcare Simulation: Surgery and Surgical Subspecialties. Comprehensive Healthcare Simulation. In: s.1.:Springer.

Stefanidis, D., (2015), Simulation in Surgery. Annals of Surgery, 261(5), p. 846-853.

Stewart, T., (2005), Dealing with Uncertainties in MCDA. In: Multiple Criteria Decision Analysis: State of the Art Surveys. New York: Springer, pp. 445-466.

Stojić, G., Stević, Ž., Antuchevičienè, J., Pamučar, D., and Vasiljević, M. (2018), "A novel rough WASPAS approach for supplier selection in a company manufacturing PVC carpentry products", Information, 9(5), pp. 121-135. 
Stuart, T. and Sorenson, O., (2003), The geography of opportunity: spatial heterogeneity in founding rates and the performance of biotechnology firms. Research Policy, 32(2), p. 229-253.

Sun, S., (2019), Enriching innovation ecosystems: The role of government in a university science park. Global Transitions, Vol. 1, pp. 104-119.

Tadić, S., Krstić, M., Roso, V. and Brnjac, N., (2020), Dry Port Terminal Location Selection by Applying the Hybrid Grey MCDM Model. Sustainability, 12(17), pp. 69-83.

Tang, R., (2017), Research for Local Universities of Science and Technology Park Innovation Management. s.1., s.n., pp. 191-194.

Turskis, Z., Goranin, N., Nurusheva, A., and Boranbayev, S., (2019), A Fuzzy WASPAS-Based Approach to Determine Critical Information Infrastructures of EU Sustainable Development. sustainability, 11(2), pp. 1-25.

Vásquez-Urriago, A., Barge-Gil, A. and Modrego Rico, A., (2016), Science and Technology Parks and cooperation for innovation: Empirical evidence from Spain. Research Policy, 45(1), pp. 137-147.

Wang, C.N., Nguyen, V., Thai, H. and Duong, D., (2018), Multi-Criteria Decision Making (MCDM) Approaches for Solar Power Plant Location Selection in Viet Nam. Energies, 11(6), p. 1504.

Wang, R., Li, X., Li, F. and Xu, C., (2020), Study on location decision framework of electric vehicle battery swapping station: Using a hybrid MCDM method. Sustainable Cities and Society, pp. 102-149.

Wang, W. and Liu, X., (2012), Intuitionistic Fuzzy Information Aggregation Using Einstein Operations. IEEE Transactions On Fuzzy Systems, 20(5), pp. 923-938.

Wan, S. P., and Li, D. F., (2013), Fuzzy LINMAP approach to heterogeneous MADM considering comparisons of alternatives with hesitation degrees. Omega, pp. 925-940.

Wei, C., Tang, X. and Wang, X., (2013), Linguistic Multi-Attribute Decision Making with a Prioritization Relationship. International Journal of Knowledge and Systems Science, 4(4), pp. 46-54.

Williams, C., Colovic, A. and Zhu, J., (2017), Integration-responsiveness, local hires and subsidiary performance amidst turbulence: Insights from a survey of Chinese subsidiaries. Journal of World Business, 52(6), p. 842-853.

Xue, Y. and Deng, Y., (2021), Decision making under measure-based granular uncertainty with intuitionistic fuzzy sets. Applied Intelligence.

Yadegaridehkordi, E., (2020), Assessment of sustainability indicators for green building manufacturing using fuzzy multi-criteria decision-making approach. Journal of Cleaner Production, Vol. 277.

Yaping, L., (2016), Problems on Solving Matrix Aggregation in Group Decision-Making by Glowworm Swarm Optimization. Mathematical problem in engineering, Vol. 7, pp. 1-8.

Yingying, L., Jindong, Q., Martínez, L. and Jun, L., (2020), A heterogeneous QUALIFLEX method with criteria interaction for multi-criteria group decision making. Information Sciences, Vol. 512, pp. 1481-1502.

Yu, G.F., Li, D.F. and Fei, W., (2018), A novel method for heterogeneous multi-attribute group decision making with preference deviation. Computers and Industrial Engineering, pp. 58-64.

Zavadskas, E. K., Antucheviciene, J., Razavi Hajiagha, S. H. and Hashemi, S. H., (2015), The interval-valued intuitionistic fuzzy MULTIMOORA method for group decision making in engineering. Mathematical Problems in Engineering, pp. 1-13.

Zavadskas, E.K., Antucheviciene, J., Razavi Hajiagha, H. and Hashemi, S.S., (2014), Extension of weighted aggregated sum product assessment with interval-valued intuitionistic fuzzy numbers (WASPAS-IVIF), Applied Soft Computing, Vol. 24, pp. 1013-1021.

Zavadskas, E.K., Turskis, Z., Antucheviciene, J. and Zakarevicius, A., (2012), Optimization of Weighted Aggregated Sum Product Assessment.. Elektronika ir Elektrotechnika, Vol 6, pp. 3-6.

Zavadskas, E.K., Turskis, Z. and Antucheviciene, J., (2015), Selecting a Contractor by Using a Novel Method for Multiple Attribute Analysis: Weighted Aggregated Sum Product Assessment with Grey Values (WASPASG), Studies in Informatics and Control, 24(2), pp. 141-150.

Zhang, Z., (2012), A Type of Score Function on Intuitionistic Fuzzy Sets with Double Parameters and Its Application to Pattern Recognition and Medical Diagnosis. 2012 International Workshop on Information and Electronics Engineering (IWIEE), pp. 4336-4342.

Zha, S., Guo, Y., Huang, S. and Wang, S., (2020), A Hybrid MCDM Method Using Combination Weight for the Selection of Facility Layout in the Manufacturing System: A Case Study. Mathematical Problem in Engineering. 


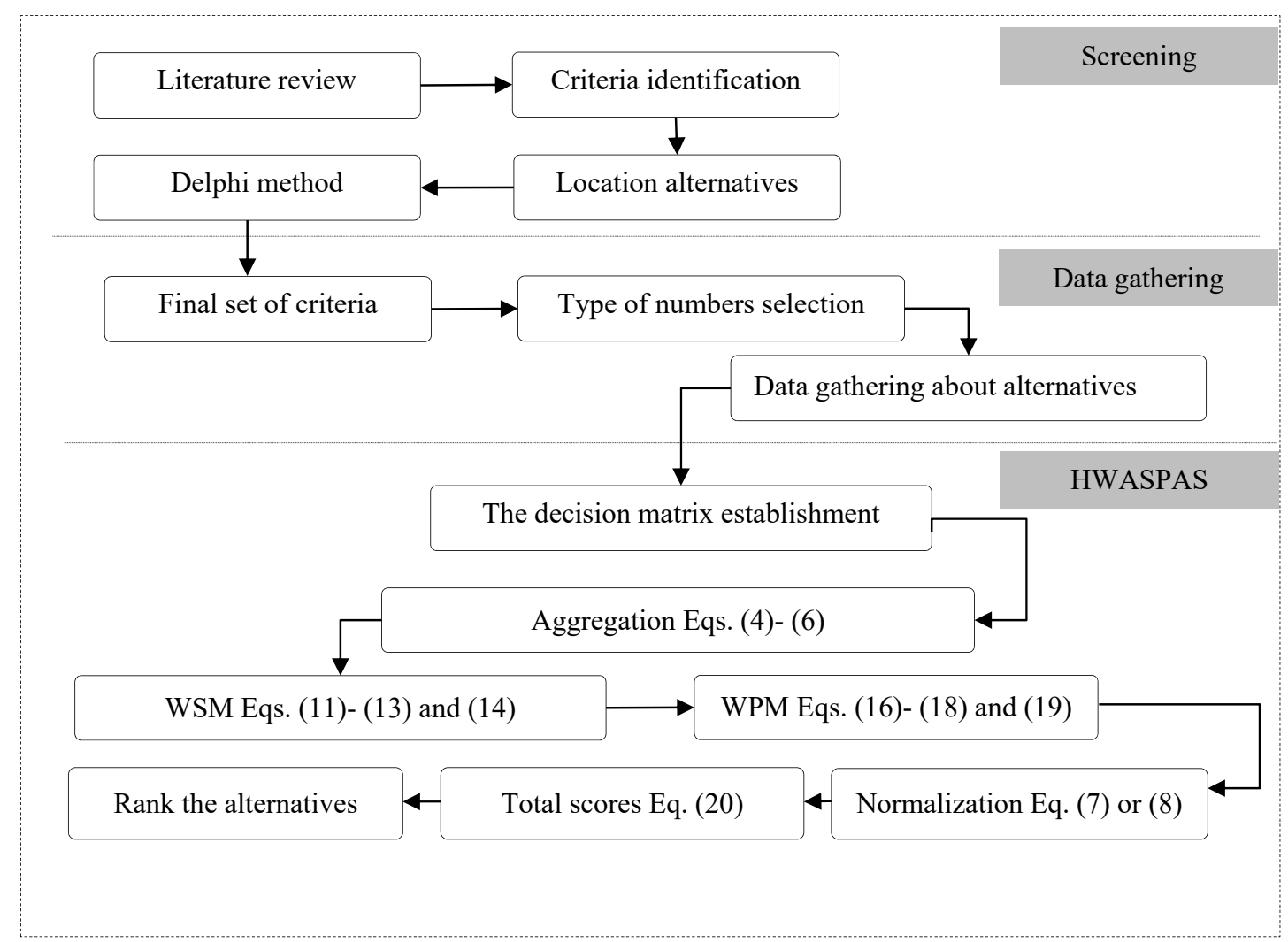

Figure 1. Methodology of the proposed approach 


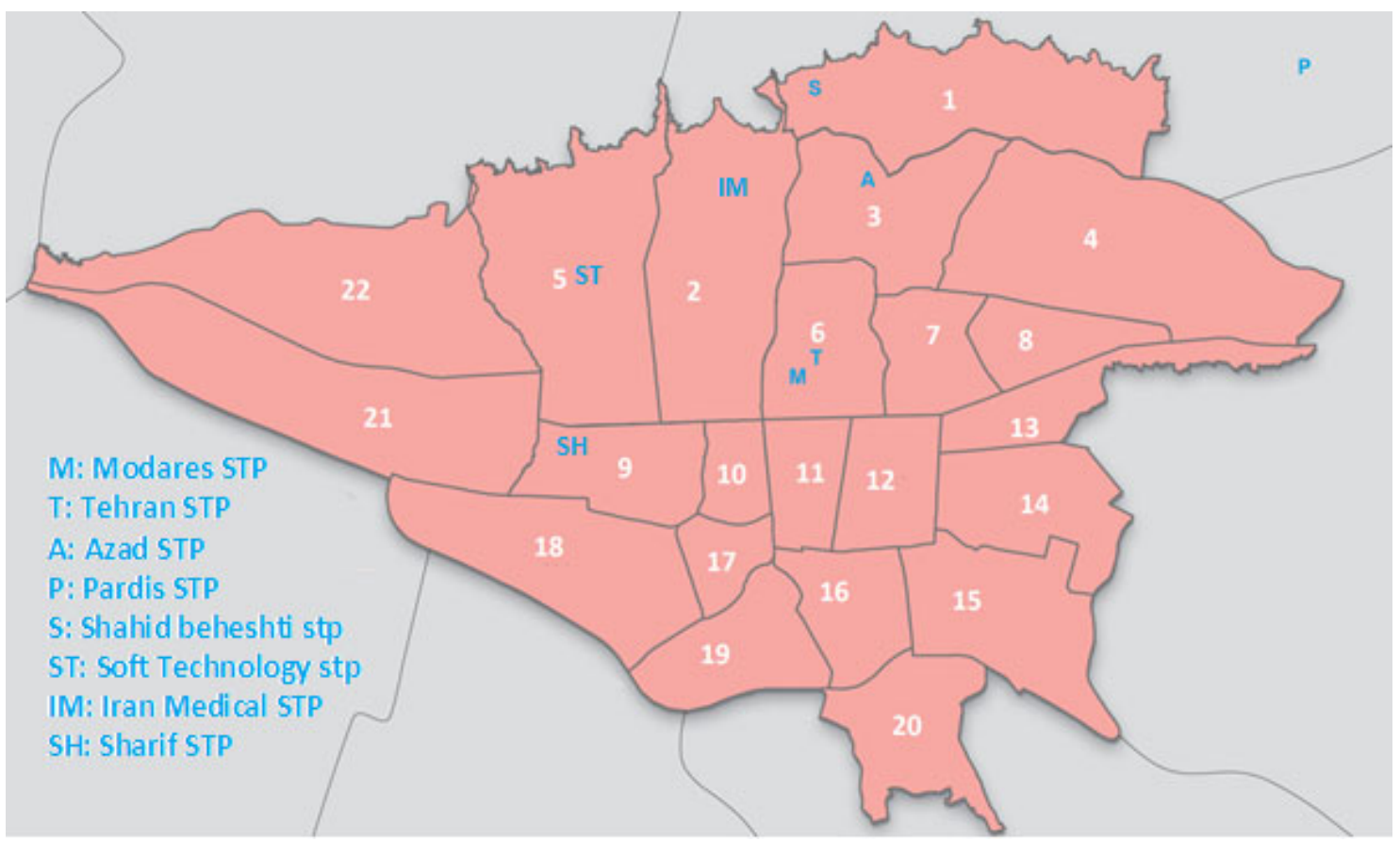

Figure 2. Tehran Map to indicate the STPs' locations 


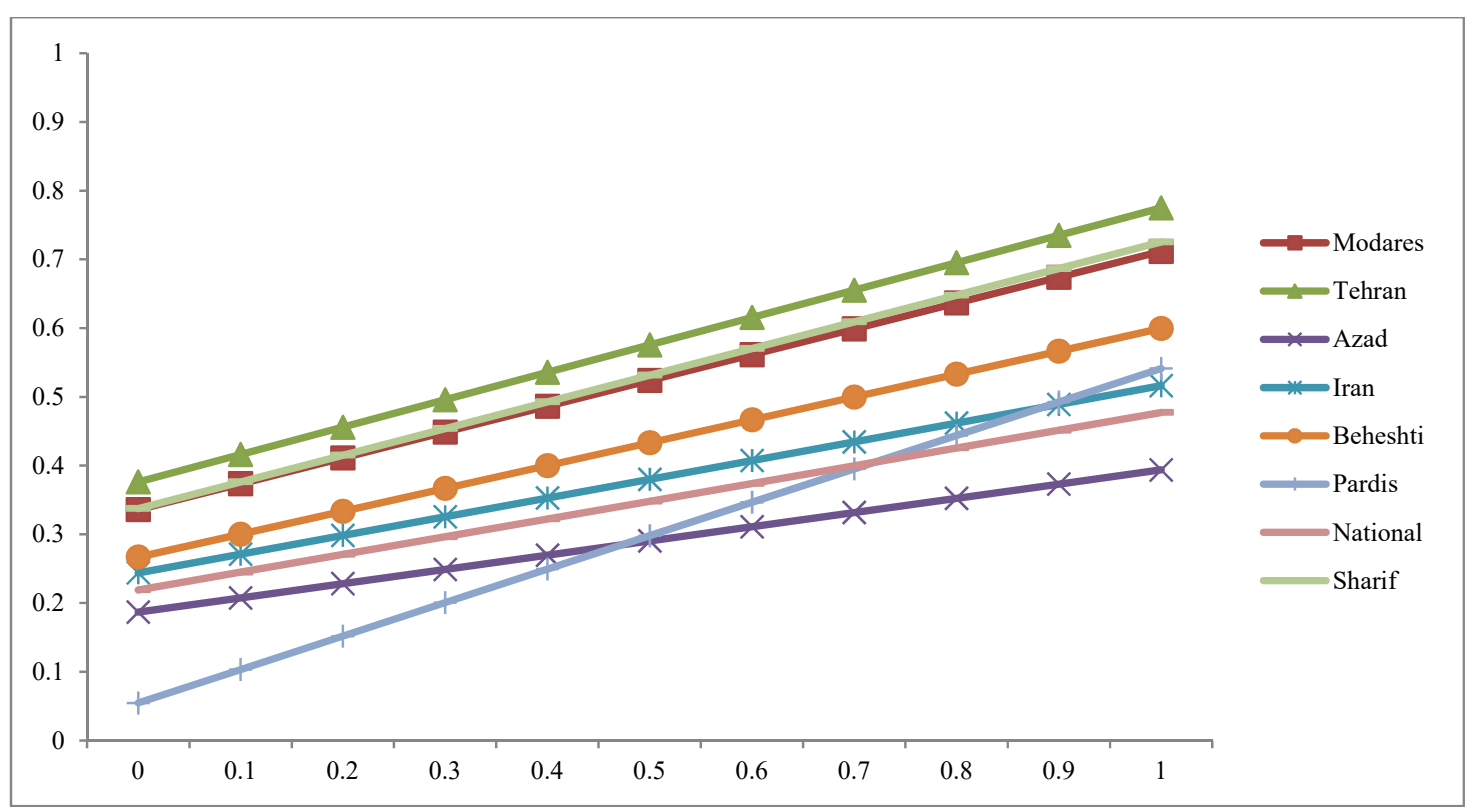

Figure 3. Aggregated ranking of alternatives based on different $\lambda$ 


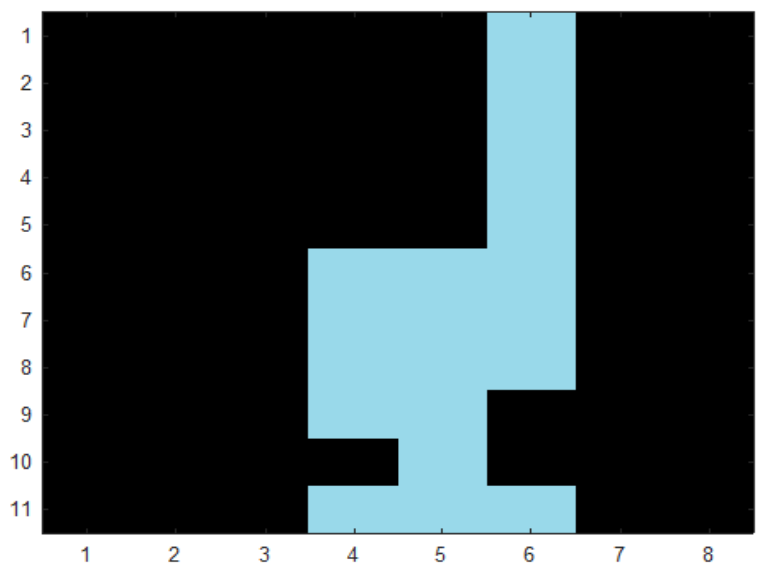

Figure $4^{\text {a }}$. Matching $1^{\text {st }}$ group ranking with aggregated ranking

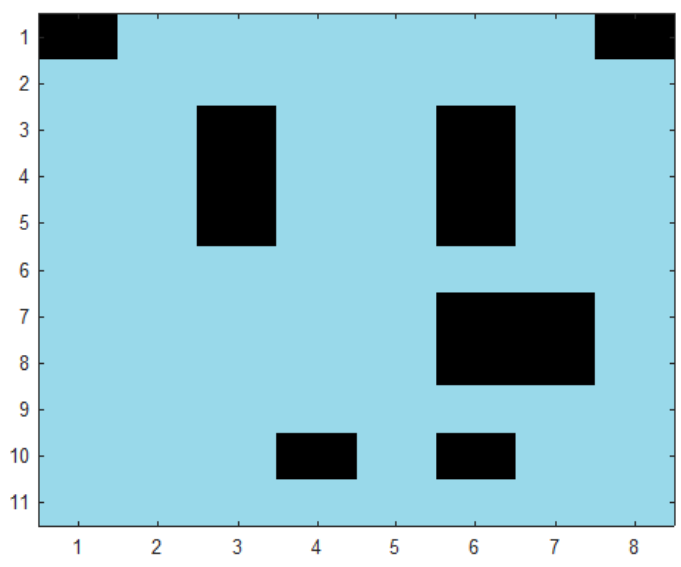

Figure $4^{\text {b }}$. Matching $2^{\text {nd }}$ group ranking with aggregated ranking

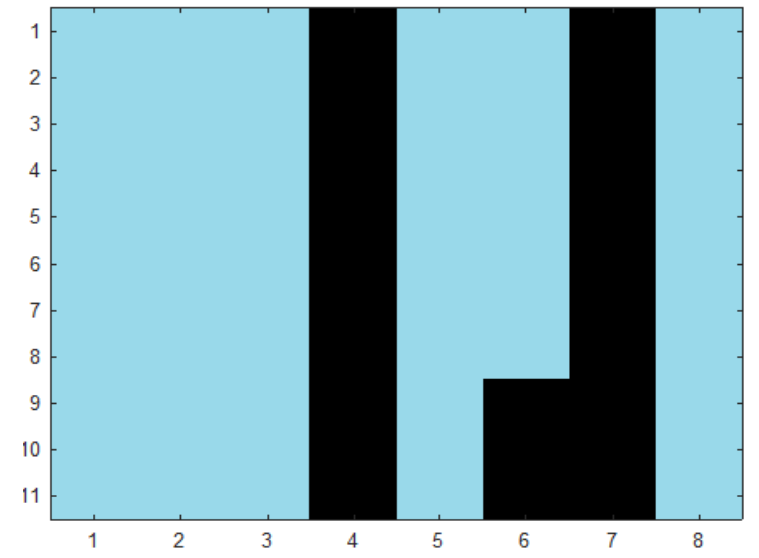

Figure $4^{\mathfrak{c}}$. Matching $3^{\text {rd }}$ group ranking with aggregated ranking 


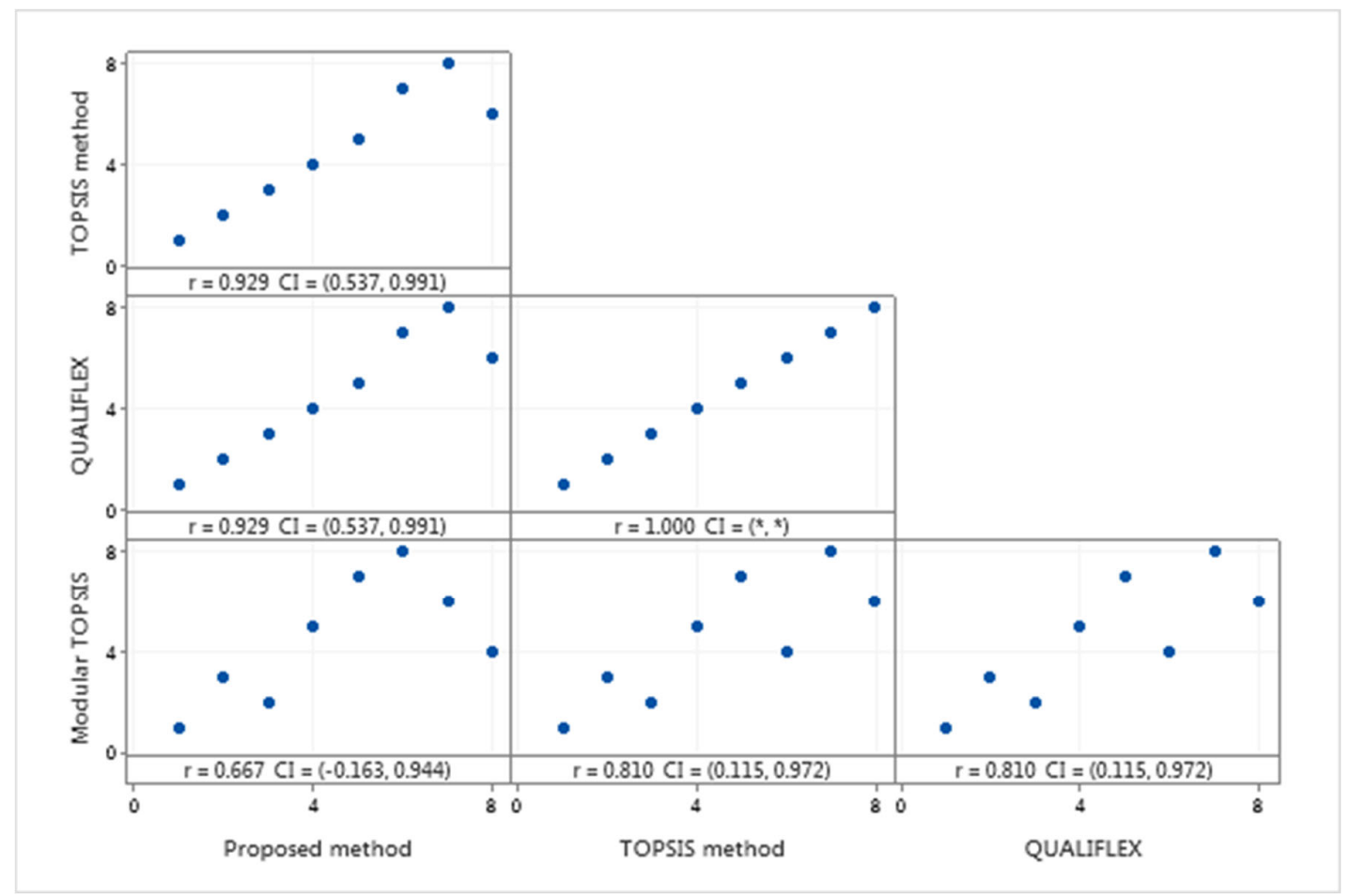

Figure 5. Ranking correlation among different methods 
Table 2. the list of criteria obtained from the literature review

\begin{tabular}{llllll}
\hline No & Criteria & No & Criteria & No & Criteria \\
\hline 1 & $\begin{array}{l}\text { Equipment purchasing } \\
\text { cost, }\end{array}$ & 9 & Space utilization, & 17 & Geographical characteristics, \\
2 & $\begin{array}{l}\text { Annual operation and } \\
\text { maintenance cost, }\end{array}$ & 10 & Transportation performance, & 18 & Transportation characteristics, \\
3 & $\begin{array}{l}\text { Service ability; } \\
\text { the largest weight for }\end{array}$ & 11 & Personnel issue & 19 & Socio-political \\
& $\begin{array}{l}\text { equipment purchasing cost } \\
5\end{array}$ & 12 & Layout flexibility & 20 & Cost \\
6 & $\begin{array}{l}\text { Close to market } \\
7\end{array}$ & 13 & Subsidiary costs & 21 & Cooperation \\
& Infrastructures & 14 & Homogeneity & 22 & The rent amount \\
8 & Preservation of Prestige & 16 & $\begin{array}{l}\text { Public/private meeting room } \\
\text { and hall }\end{array}$ & 23 & Possibility of development \\
\hline
\end{tabular}


Table 3. Extracted attributes, their type, and definition from Two round Delphi

\begin{tabular}{|c|c|c|c|}
\hline Attributes & Description & $\begin{array}{l}\text { Nature of } \\
\text { attributes }\end{array}$ & Resource \\
\hline The rent amount & $\begin{array}{l}\text { The rate of rent for each room in different } \\
\text { STPs varies, therefore it can be } \\
\text { considered as an important and main cost } \\
\text { factor for location problems. It's an } \\
\text { effective factor that many decisions are } \\
\text { made on it. }\end{array}$ & Cost & $\begin{array}{l}\text { Khaengkhan et al. 2019; Ulutaş et } \\
\text { al., 2020; Mihajlović et al., 2019; } \\
\text { Hashemnkhani Zolfani et al., 2013) }\end{array}$ \\
\hline Accessibility & $\begin{array}{l}\text { It seems more comfortable for managers } \\
\text { and staff if the central office is located } \\
\text { close to public transportation systems } \\
\text { such as bus stations, Metro stations, and } \\
\text { taxi lines. It reduces the Commuting costs } \\
\text { for personnel. }\end{array}$ & Benefit & $\begin{array}{l}\text { Khaengkhan et al. 2019; Aydin and } \\
\text { Seker 2021; Zha et al., 2020; } \\
\text { Karaşan et al., 2018; Hashemkhani } \\
\text { Zolfani et al., 2013) }\end{array}$ \\
\hline Homogeneity & $\begin{array}{l}\text { The close relationship among similar } \\
\text { businesses as neighbor companies helps } \\
\text { their managers find related resources } \\
\text { easily and quickly. The suppliers prefer } \\
\text { and tend to find their customers in } \\
\text { colonies too. }\end{array}$ & Benefit & $\begin{array}{l}\text { Extracted from interviews with } \\
\text { international entrepreneurs }\end{array}$ \\
\hline $\begin{array}{l}\text { Public/private } \\
\text { meeting room and } \\
\text { hall }\end{array}$ & $\begin{array}{l}\text { There are some meeting rooms and } \\
\text { central halls in STPs, and startups can use } \\
\text { them for free or in very low payments. } \\
\text { These facilities are necessary for business } \\
\text { meetings and negotiations. }\end{array}$ & Benefit & $\begin{array}{l}\text { Extracted from interviews with } \\
\text { international entrepreneurs }\end{array}$ \\
\hline Infrastructures & $\begin{array}{l}\text { The Phoneline subscription and internet } \\
\text { access are usually provided from one } \\
\text { source in some STPs and they are } \\
\text { optional in some others; Hence the startup } \\
\text { managers need to provide them by } \\
\text { themselves. Therefore, these } \\
\text { infrastructures might be added } \\
\text { advantages. }\end{array}$ & Benefit & $\begin{array}{l}\text { (Karagoz et al., 2020; Tadić et al., } \\
\text { 2020; Zečević et al., 2017) }\end{array}$ \\
\hline Close to market & $\begin{array}{l}\text { Access to the market is the main goal of } \\
\text { each business to present the products. } \\
\text { Some startups are b2b and some of them } \\
\text { are B2C; therefore, the second group } \\
\text { needs to access retailers to distribute the } \\
\text { products to end-users. }\end{array}$ & Benefit & $\begin{array}{l}\text { Khaengkhan et al. 2019; Aydin and } \\
\text { Seker 2021, Zečević et al., 2017) }\end{array}$ \\
\hline Subsidiary costs & $\begin{array}{l}\text { Rent a room in STPs includes subsidiary } \\
\text { costs such as charges for office units, } \\
\text { office learning costs, parking fees, etc. } \\
\text { The lower the subsidiary cost, the more } \\
\text { suitable choice is to rent. }\end{array}$ & Cost & $\begin{array}{l}\text { Khaengkhan et al. 2019; Aydin and } \\
\text { Seker 2021; Ak and Acar, 2021; } \\
\text { Wang et al., 2020; Karagoz et al., } \\
\text { 2020; Tadić et al., 2020) }\end{array}$ \\
\hline $\begin{array}{l}\text { Preservation of } \\
\text { Prestige }\end{array}$ & $\begin{array}{l}\text { STPs are dependent on universities; } \\
\text { therefore, the fame of universities } \\
\text { influences STP acceptance in society. } \\
\text { Subsequently, the location is impressed } \\
\text { by University Name and Brand. }\end{array}$ & Benefit & $\begin{array}{l}\text { Extracted from interviews with } \\
\text { international entrepreneurs }\end{array}$ \\
\hline $\begin{array}{l}\text { Possibility of } \\
\text { development }\end{array}$ & $\begin{array}{l}\text { Some STPs are located in a limited area } \\
\text { and some of them are likely to be } \\
\text { extended in several buildings. Therefore, } \\
\text { the startups can extend their activities in } \\
\text { these STPs. }\end{array}$ & Benefit & $\begin{array}{l}\text { (Aydin and Seker, 2021; Zha et al., } \\
\text { 2020; Hashemkhani Zolfani et al., } \\
\text { 2013) }\end{array}$ \\
\hline $\begin{array}{l}\text { International } \\
\text { collaboration }\end{array}$ & $\begin{array}{l}\text { These parks have separate connections } \\
\text { with international commissions and } \\
\text { relationships with other nations parks } \\
\text { that can provide them with more } \\
\text { information and international } \\
\text { collaborations. }\end{array}$ & Benefit & (Ak and Acar, 2021) \\
\hline
\end{tabular}


Table 4. TFNs (Chin et al., 2006), INNs (Zavadskas et al., 2015) and IFNs (Schitea et al., 2019)

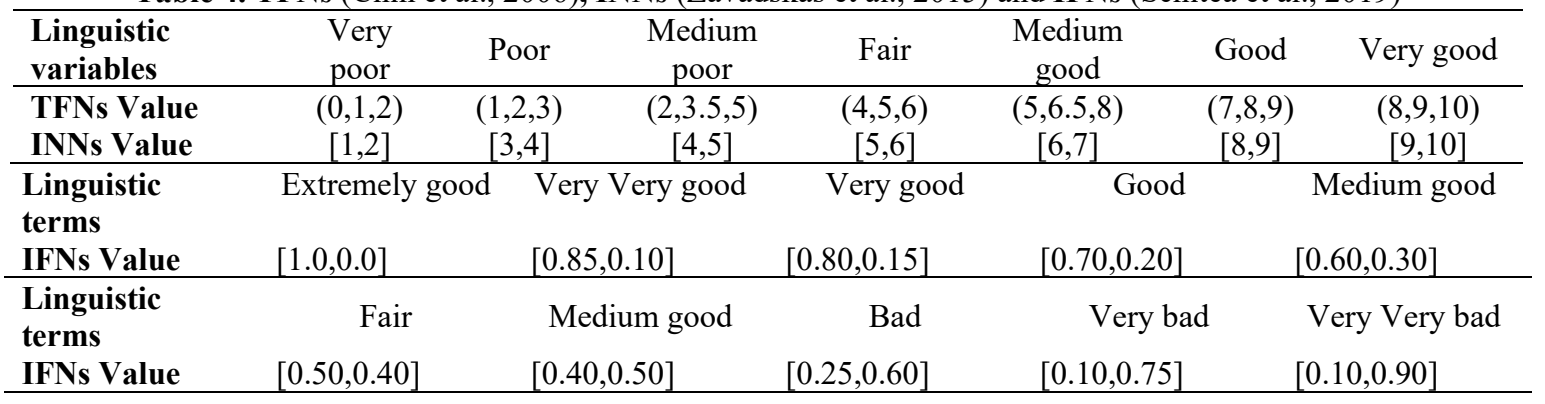


Table 5. Groups of expert decision matrix

\begin{tabular}{|c|c|c|c|c|c|c|c|c|c|c|}
\hline Criteria & 1 & 2 & 3 & 4 & 5 & 6 & 7 & 8 & 9 & 10 \\
\hline \multicolumn{11}{|c|}{ First Group of expert decision matrix } \\
\hline Modares & $\begin{array}{c}48,000 \\
56,000]\end{array}$ & $(4,5,6)$ & {$[6,7]$} & 2 & $(7,8,9)$ & $(5,6.5,8)$ & $\begin{array}{l}10,000 \\
15,000]\end{array}$ & $(5,6.5,8)$ & {$[0.80,0.15]$} & {$[0.50,0.40]$} \\
\hline Tehran & $\begin{array}{l}{[50,000 ;} \\
85,000]\end{array}$ & $(4,5,6)$ & {$[6,7]$} & 11 & $(4,5,6)$ & $(5,6.5,8)$ & $\begin{array}{l}{[20,000} \\
25,000]\end{array}$ & $(5,6.5,8)$ & {$[0.70,0.20]$} & {$[0.70,0.20]$} \\
\hline Azad & $\begin{array}{l}{[80,000} \\
100,000]\end{array}$ & $(2,3.5,5)$ & {$[3,4]$} & 2 & $(2,3.5,5)$ & $(5,6.5,8)$ & $\begin{array}{c}{[35,000} \\
50,000]\end{array}$ & $(1,2,3)$ & {$[0.60,0.30]$} & {$[0.50,0.40]$} \\
\hline Iran & $\begin{array}{l}{[50,000} \\
70,000]\end{array}$ & $(1,2,3)$ & {$[3,4]$} & 2 & $(1,2,3)$ & $(2,3.5,5)$ & $\begin{array}{l}{[10,000} \\
20,000]\end{array}$ & $(5,6.5,8)$ & {$[0.50,0.40]$} & {$[0.25,0.60]$} \\
\hline Beheshti & $\begin{array}{l}{[60,000} \\
80,000]\end{array}$ & $(0,1,2)$ & {$[6,7]$} & 1 & $(8,9,10)$ & $(1,2,3)$ & $\begin{array}{l}{[25,000} \\
35,000]\end{array}$ & $(5,6.5,8)$ & {$[0.50,0.40]$} & {$[0.50,0.40]$} \\
\hline Pardis & $\begin{array}{c}{[120,000} \\
140,000]\end{array}$ & $(0,1,2)$ & {$[1,2]$} & 8 & $(8,9,10)$ & $(0,1,2)$ & $\begin{array}{c}{[50,000} \\
65,000]\end{array}$ & $(4,5,6)$ & {$[0.80,0.15]$} & {$[0.80,0.15]$} \\
\hline National & $\begin{array}{c}{[40,000} \\
65,000]\end{array}$ & $(1,2,3)$ & {$[1,2]$} & 1 & $(2,3.5,5)$ & $(1,2,3)$ & $\begin{array}{c}{[10,000} \\
15,000]\end{array}$ & $(1,2,3)$ & {$[0.10,0.90]$} & {$[0.25,0.60]$} \\
\hline Sharif & $\begin{array}{c}{[55,000} \\
85,000]\end{array}$ & $(2,3.5,5)$ & {$[3,4]$} & 6 & $(8,9,10)$ & $(2,3.5,5)$ & $\begin{array}{l}{[30,000} \\
35,000]\end{array}$ & $(5,6.5,8)$ & {$[0.80,0.15]$} & {$[0.80,0.15]$} \\
\hline \multicolumn{11}{|c|}{ Second Group of expert decision matrix } \\
\hline Modares & $\begin{array}{c}48,000 \\
56,000]\end{array}$ & $(5,6.5,8)$ & {$[5,6]$} & 2 & $(5,6.5,8)$ & $(4,5,6)$ & $\begin{array}{c}10,000 ; \\
15,000]\end{array}$ & $(4,5,6)$ & {$[0.70,0.20]$} & {$[0.25,0.60]$} \\
\hline Tehran & $\begin{array}{l}{[50,000} \\
85,000]\end{array}$ & $(4,5,6)$ & {$[5,6]$} & 11 & $(8,9,10)$ & $(5,6.5,8)$ & $\begin{array}{l}{[20,000} \\
25,000]\end{array}$ & $(7,8,9)$ & {$[0.70,0.20]$} & {$[0.10,0.75]$} \\
\hline Azad & $\begin{array}{l}{[80,000} \\
100,000]\end{array}$ & $(1,2,3)$ & {$[3,4]$} & 2 & $(2,3.5,5)$ & $(4,5,6)$ & $\begin{array}{c}{[35,000} \\
50,000]\end{array}$ & $(0,1,2)$ & {$[0.10,0.75]$} & {$[0.10,0.75]$} \\
\hline Iran & $\begin{array}{l}{[50,000} \\
70,000]\end{array}$ & $(2,3.5,5)$ & {$[1,2]$} & 2 & $(2,3.5,5)$ & $(4,5,6)$ & $\begin{array}{l}{[10,000} \\
20,000]\end{array}$ & $(4,5,6)$ & {$[0.70,0.20]$} & {$[0.10,0.75]$} \\
\hline Beheshti & $\begin{array}{l}{[60,000} \\
80,000]\end{array}$ & $(1,2,3)$ & {$[5,6]$} & 1 & $(7,8,9)$ & $(1,2,3)$ & $\begin{array}{l}{[25,000} \\
35,000]\end{array}$ & $(5,6.5,8)$ & {$[0.70,0.20]$} & {$[0.25,0.60]$} \\
\hline Pardis & $\begin{array}{r}{[120,000} \\
140,000]\end{array}$ & $(1,2,3)$ & {$[1,2]$} & 8 & $(7,8,9)$ & $(1,2,3)$ & $\begin{array}{c}{[50,000} \\
65,000]\end{array}$ & $(5,6.5,8)$ & {$[0.80,0.15]$} & {$[0.80,0.15]$} \\
\hline National & $\begin{array}{c}{[40,000 ;} \\
65,000]\end{array}$ & $(0,1,2)$ & {$[3,4]$} & 1 & $(4,5,6)$ & $(4,5,6)$ & $\begin{array}{c}{[10,000} \\
15,000]\end{array}$ & $(4,5,6)$ & {$[0.25,0.60]$} & {$[0.10,0.75]$} \\
\hline Sharif & $\begin{array}{c}{[55,000} \\
85,000]\end{array}$ & $(2,3.5,5)$ & {$[5,6]$} & 6 & $(7,8,9)$ & $(4,5,6)$ & $\begin{array}{l}{[30,000} \\
35,000]\end{array}$ & $(4,5,6)$ & {$[0.85,0.10]$} & {$[0.80,0.15]$} \\
\hline \multicolumn{11}{|c|}{ Third Group of expert decision matrix } \\
\hline Modares & $\begin{array}{c}{[48,000 ;} \\
56,000]\end{array}$ & $(7,8,9)$ & {$[5,6]$} & 2 & $(4,5,6)$ & $(5,6.5,8)$ & $\begin{array}{c}10,000 \\
15,000]\end{array}$ & $(4,5,6)$ & {$[0.80,0.15]$} & {$[0.10,0.75]$} \\
\hline Tehran & $\begin{array}{l}{[50,000} \\
85,000]\end{array}$ & $(7,8,9)$ & {$[6,7]$} & 11 & $(7,8,9)$ & $(5,6.5,8)$ & $\begin{array}{l}{[20,000} \\
25,000]\end{array}$ & $(4,5,6)$ & {$[0.80,0.15]$} & {$[0.85,0.10]$} \\
\hline Azad & $\begin{array}{l}{[80,000 ;} \\
100,000]\end{array}$ & $(2,3.5,5)$ & {$[4,5]$} & 2 & $(4,5,6)$ & $(1,2,3)$ & $\begin{array}{c}{[35,000} \\
50,000]\end{array}$ & $(1,2,3)$ & {$[0.70,0.20]$} & {$[0.10,0.90]$} \\
\hline Iran & $\begin{array}{l}{[50,000 ;} \\
70,000]\end{array}$ & $(4,5,6)$ & {$[3,4]$} & 2 & $(4,5,6)$ & $(5,6.5,8)$ & $\begin{array}{l}{[10,000} \\
20,000]\end{array}$ & $(5,6.5,8)$ & {$[0.10,0.75]$} & {$[0.10,0.90]$} \\
\hline Beheshti & $\begin{array}{c}{[60,000} \\
80,000]\end{array}$ & $(4,5,6)$ & {$[6,7]$} & 1 & $(5,6.5,8)$ & $(2,3.5,5)$ & $\begin{array}{l}{[25,000} \\
35,000]\end{array}$ & $(4,5,6)$ & {$[0.80,0.15]$} & {$[0.85,0.10]$} \\
\hline Pardis & $\begin{array}{c}{[120,000} \\
140,000]\end{array}$ & $(5,6.5,8)$ & {$[1,2]$} & 8 & $(5,6.5,8)$ & $(2,3.5,5)$ & $\begin{array}{c}{[50,000} \\
65,000]\end{array}$ & $(4,5,6)$ & {$[0.70,0.20]$} & {$[0.80,0.15]$} \\
\hline National & $\begin{array}{c}{[40,000} \\
65,000]\end{array}$ & $(2,3.5,5)$ & {$[5,6]$} & 1 & $(5,6.5,8)$ & $(2,3.5,5)$ & $\begin{array}{l}{[10,000} \\
15,000]\end{array}$ & $(5,6.5,8)$ & {$[0.80,0.15]$} & {$[0.10,0.75]$} \\
\hline Sharif & $\begin{array}{c}{[55,000} \\
85,000]\end{array}$ & $(7,8,9)$ & {$[5,6]$} & 6 & $(4,5,6)$ & $(5,6.5,8)$ & $\begin{array}{l}{[30,000} \\
35,000]\end{array}$ & $(4,5,6)$ & {$[0.85,0.10]$} & {$[0.85,0.10]$} \\
\hline
\end{tabular}


Table 6. The weights of attributes

\begin{tabular}{ccccccccccc}
\hline Attributes & 1 & 2 & 3 & 4 & 5 & 6 & 7 & 8 & 9 & 10 \\
\hline Weights & 0.173 & 0.155 & 0.045 & 0.045 & 0.127 & 0.082 & 0.045 & 0.136 & 0.109 & 0.082 \\
\hline
\end{tabular}


Table 7. Aggregated decision matrix

\begin{tabular}{|c|c|c|c|c|c|c|c|c|c|c|}
\hline Criteria & 1 & 2 & 3 & 4 & 5 & 6 & 7 & 8 & 9 & 10 \\
\hline Modares & $\begin{array}{l}{[48,000 ;} \\
56,000]\end{array}$ & $(5.33,6.5,7.67)$ & {$[5.33,6.33]$} & 2 & $(5.33,6.5,7.67)$ & $(4.67,6.00,7.33)$ & $\begin{array}{l}{[10,000 ;} \\
15,000]\end{array}$ & $(4.33,5.50,6.67)$ & {$[0.771,0.005]$} & {$[0.304,0.180]$} \\
\hline Tehran & $\begin{array}{l}{[50,000} \\
85,000]\end{array}$ & $(5.00,6.00,7.00)$ & {$[5.67,6.67]$} & 11 & $(6.33,7.33,8.33)$ & $(5.00,6.50,8.00)$ & $\begin{array}{l}{[20,000 ;} \\
25,000]\end{array}$ & $(5.33,6.5,7.67)$ & {$[0.738,0.006]$} & {$[0.657,0.015]$} \\
\hline Azad & $\begin{array}{l}{[80,000} \\
100,000]\end{array}$ & $(1.67,3.00,4.33)$ & {$[3.33,4.33]$} & 2 & $(2.67,4.00,5.33)$ & $(3.33,4.50,5.67)$ & $\begin{array}{c}{[35,000 ;} \\
50,000]\end{array}$ & $(0.67,1.67,2.67)$ & {$[0.524,0.045]$} & {$[0.260,0.270]$} \\
\hline Iran & $\begin{array}{l}{[50,000 ;} \\
70,000]\end{array}$ & $(2.33,3.50,4.67)$ & {$[2.33,3.33]$} & 2 & $(2.33,3.50,4.67)$ & $(3.67,5.00,6.33)$ & $\begin{array}{l}{[10,000 ;} \\
20,000]\end{array}$ & $(4.67,6.00,7.33)$ & {$[0.487,0.060]$} & {$[0.153,0.405]$} \\
\hline Beheshti & $\begin{array}{l}{[60,000 ;} \\
80,000]\end{array}$ & $(1.67,2.67,3.67)$ & {$[5.67,6.67]$} & 1 & $(6.67,7.83,9.00)$ & $(1.33,2.50,3.67)$ & $\begin{array}{l}{[25,000 ;} \\
35,000]\end{array}$ & $(4.67,6.00,7.33)$ & {$[0.689,0.012]$} & {$[0.617,0.023]$} \\
\hline Pardis & $\begin{array}{c}{[120,000 ;} \\
140,000]\end{array}$ & $(2.00,3.17,4.33)$ & {$[1.00,2.00]$} & 8 & $(6.67,7.83,9.00)$ & $(1.00,2.17,3.33)$ & $\begin{array}{l}{[50,000 ;} \\
65,000]\end{array}$ & $(4.33,5.50,6.67)$ & {$[0.771,0.005]$} & {$[0.800,0.003]$} \\
\hline National & $\begin{array}{l}{[40,000 ;} \\
65,000]\end{array}$ & $(1.00,2.17,3.33)$ & {$[3.00,4.00]$} & 1 & $(3.67,5 \cdot 00,6.33)$ & $(2.33,3.50,4.67)$ & $\begin{array}{l}{[10,000 ;} \\
15,000]\end{array}$ & $(3.33,4.50,5.67)$ & {$[0.487,0.081]$} & {$[0.153,0.338]$} \\
\hline Sharif & $\begin{array}{l}{[55,000} \\
85,000] \\
\end{array}$ & $(3.67,5.00 .6 .33)$ & {$[4.33,5.33]$} & 6 & $(6.33,7.33,8.33)$ & $(3.67,5.00,6.33)$ & $\begin{array}{l}{[30,000 ;} \\
35,000]\end{array}$ & $(4.33,5.50,6.67)$ & {$[0.835,0.002]$} & {$[0.818,0.002]$} \\
\hline
\end{tabular}


Table 8. Normalized decision matrix

\begin{tabular}{ccccccccccc}
\hline Criteria & $\mathbf{1}$ & $\mathbf{2}$ & $\mathbf{3}$ & $\mathbf{4}$ & $\mathbf{5}$ & $\mathbf{6}$ & $\mathbf{7}$ & $\mathbf{8}$ & $\mathbf{9}$ \\
\hline Modares & {$[0.60,0.66]$} & $(0.70,0.85,1.00)$ & {$[0.80,0.95]$} & 0.18 & $(0.59,0.72,0.85)$ & $(0.58,0.75,0.92)$ & {$[0.77,0.85]$} & $(0.57,0.72,0.87)$ & {$[0.0012,0.8356]$} & {$[0.0007,0.8510]$} \\
Tehran & {$[0.39,0.64]$} & $(0.65,0.78,0.91)$ & {$[0.85,1.00]$} & 1.00 & $(0.70,0.81,0.93)$ & $(0.63,0.81,1.00)$ & {$[0.62,0.69]$} & $(0.70,0.85,1.00)$ & {$[0.0011,0.8359]$} & {$[0.0015,0.8210]$} \\
Azad & {$[0.29,0.43]$} & $(0.22,0.39,0.57)$ & {$[0.50,0.65]$} & 0.18 & $(0.30,0.44,0.59)$ & $(0.42,0.56,0.71)$ & {$[0.23,0.46]$} & $(0.09,0.22,0.35)$ & {$[0.0008,0.8423]$} & {$[0.0006,0.8674]$} \\
Iran & {$[0.50,0.64]$} & $(0.30,0.46,0.61)$ & {$[0.35,0.50]$} & 0.18 & $(0.26,0.39,0.52)$ & $(0.46,0.63,0.79)$ & {$[0.69,0.85]$} & $(0.61,0.78,0.96)$ & {$[0.0007,0.8448]$} & {$[0.0003,0.8919]$} \\
Beheshti & {$[0.43,0.57]$} & $(0.22,0.35,0.48)$ & {$[0.85,1.00]$} & 0.09 & $(0.74,0.87,1.00)$ & $(0.17,0.31,0.46)$ & {$[0.46,0.62]$} & $(0.61,0.78,0.96)$ & {$[0.0010,0.8369]$} & {$[0.0014,0.8226]$} \\
Pardis & {$[0.00,0.14]$} & $(0.26,0.41,0.57)$ & {$[0.15,0.30]$} & 0.73 & $(0.74,0.87,1.00)$ & $(0.13,0.27,0.42)$ & {$[0.00,0.23]$} & $(0.57,0.72,0.87)$ & {$[0.0012,0.8356]$} & {$[0.0018,0.8189]$} \\
National & {$[0.54,0.71]$} & $(0.13,0.28,0.43)$ & {$[0.45,0.60]$} & 0.09 & $(0.41,0.56,0.70)$ & $(0.29,0.44,0.58)$ & {$[0.77,0.85]$} & $(0.43,0.59,0.74)$ & {$[0.0007,0.8483]$} & {$[0.0003,0.8796]$} \\
Sharif & {$[0.39,0.61]$} & $(0.48,0.65,0.83)$ & {$[0.65,0.80]$} & 0.55 & $(0.70,0.81,0.93)$ & $(0.46,0.63,0.79)$ & {$[0.46,0.54]$} & $(0.57,0.72,0.87)$ & {$[0.0013,0.8352]$} & {$[0.0018,0.8187]$} \\
\hline
\end{tabular}


Table 9. WSM, WPM and WASPAS results

\begin{tabular}{lccccc}
\hline \multicolumn{1}{c}{ Qi } & INNs & TFNs & $\begin{array}{c}\text { Real } \\
\text { numbers }\end{array}$ & IFNs & SCORE \\
\hline \multicolumn{5}{c}{ Meighted Sum Model Results } \\
\hline Mehran & 0.184464 & 0.3822 & 0.01 & 0.031266 & $\mathbf{0 . 1 8 0 8 5 3}$ \\
Azad & 0.160637 & 0.406715 & 0.05 & 0.033899 & $\mathbf{0 . 2 1 7 1 7 4}$ \\
Iran & 0.103238 & 0.192787 & 0.01 & 0.02905 & $\mathbf{0 . 1 0 5 3 1 6}$ \\
Beheshti & 0.152598 & 0.277835 & 0.01 & 0.026656 & $\mathbf{0 . 1 4 1 8 3 4}$ \\
Pardis & 0.152356 & 0.29651 & 0.00 & 0.033635 & $\mathbf{0 . 1 4 5 8 2 1}$ \\
National & 0.027674 & 0.294332 & 0.03 & 0.03412 & $\mathbf{0 . 1 3 2 5 9 5}$ \\
Sharif & 0.168096 & 0.230061 & 0.00 & 0.02729 & $\mathbf{0 . 1 3 1 2 8 3}$ \\
\hline \multicolumn{7}{c}{0.141625} & 0.353384 & 0.02 & 0.034197 & $\mathbf{0 . 1 7 7 1 9 8}$ \\
\hline Modares & 0.908192 & 0.870261 & 0.01 & 0.382353 & $\mathbf{0 . 7 1 9 6 5 4}$ \\
Tehran & 0.868512 & 0.899278 & 0.05 & 0.39134 & $\mathbf{0 . 7 5 4 9 9 4}$ \\
Azad & 0.773694 & 0.592487 & 0.01 & 0.374351 & $\mathbf{0 . 6 0 1 3 7 7}$ \\
Iran & 0.861443 & 0.725299 & 0.01 & 0.365922 & $\mathbf{0 . 6 5 9 6 1 5}$ \\
Beheshti & 0.85784 & 0.726084 & 0.00 & 0.389827 & $\mathbf{0 . 6 6 6 4 7 2}$ \\
Pardis & 0.155895 & 0.727155 & 0.03 & 0.3936 & $\mathbf{0 . 4 6 3 2 8 1}$ \\
National & 0.885252 & 0.653362 & 0.00 & 0.36747 & $\mathbf{0 . 6 4 6 2 5}$ \\
Sharif & 0.844261 & 0.834817 & 0.02 & 0.394718 & $\mathbf{0 . 7 1 2 0 2 9}$ \\
\hline
\end{tabular}

The total score of Alternatives and the Ranking

\begin{tabular}{lcc}
\hline $\mathbf{K}_{\mathbf{i}}$ & Total Score & Rank \\
\hline Modares & 0.450254 & 2 \\
Tehran & 0.486084 & 1 \\
Azad & 0.353346 & 7 \\
Iran & 0.400725 & 5 \\
Beheshti & 0.406147 & 4 \\
Pardis & 0.297938 & 8 \\
National & 0.388767 & 6 \\
Sharif & 0.444614 & 3 \\
\hline
\end{tabular}


Table 10. Sensitivity analysis

\begin{tabular}{ccccccccc}
\hline$\lambda$ & Modares & Tehran & Azad & Iran & Beheshti & Pardis & National & Sharif \\
\hline 0 & 0.3360 & 0.3762 & 0.1868 & 0.2438 & 0.2669 & 0.0546 & 0.2190 & 0.3373 \\
0.1 & 0.3735 & 0.4161 & 0.2075 & 0.2711 & 0.3002 & 0.1033 & 0.2448 & 0.3761 \\
0.2 & 0.4111 & 0.4559 & 0.2282 & 0.2983 & 0.3334 & 0.1519 & 0.2706 & 0.4150 \\
0.3 & 0.4487 & 0.4958 & 0.2489 & 0.3256 & 0.3667 & 0.2006 & 0.2964 & 0.4538 \\
0.4 & 0.4863 & 0.5357 & 0.2696 & 0.3528 & 0.4000 & 0.2492 & 0.3223 & 0.4926 \\
0.5 & 0.5238 & 0.5756 & 0.2903 & 0.3800 & 0.4333 & 0.2979 & 0.3481 & 0.5314 \\
0.6 & 0.5614 & 0.6154 & 0.3110 & 0.4073 & 0.4665 & 0.3466 & 0.3739 & 0.5702 \\
0.7 & 0.5990 & 0.6553 & 0.3317 & 0.4345 & 0.4998 & 0.3952 & 0.3997 & 0.6090 \\
0.8 & 0.6365 & 0.6952 & 0.3524 & 0.4618 & 0.5331 & 0.4439 & 0.4256 & 0.6478 \\
0.9 & 0.6741 & 0.7350 & 0.3731 & 0.4890 & 0.5664 & 0.4926 & 0.4514 & 0.6866 \\
1 & 0.7117 & 0.7749 & 0.3938 & 0.5163 & 0.5996 & 0.5412 & 0.4772 & 0.7254 \\
\hline
\end{tabular}


Table 11. Comparing the results

\begin{tabular}{lcccc}
\hline & Proposed method & TOPSIS method & QUALIFLEX & Modular TOPSIS \\
\hline Modares & 2 & 2 & 2 & 3 \\
Tehran & 1 & 1 & 1 & 1 \\
Azad & 7 & 8 & 8 & 6 \\
Iran & 5 & 5 & 5 & 7 \\
Beheshti & 4 & 4 & 4 & 5 \\
Pardis & 8 & 6 & 6 & 4 \\
National & 6 & 7 & 7 & 8 \\
Sharif & 3 & 3 & 3 & 2 \\
\hline
\end{tabular}

